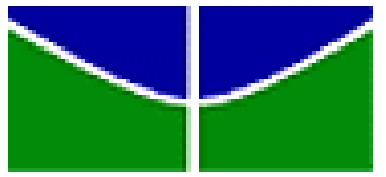

Universidade de Brasília (UnB)

Faculdade de Ciência da Informação (FCl)

Curso de Biblioteconomia

\title{
QUALIDADE DE PERIÓDICOS CIENTÍFICOS BRASILEIROS QUE UTILIZAM O SISTEMA ELETRÔNICO DE EDITORAÇÃO DE REVISTAS (SEER)
}

Autora: Luisa Veras de Sandes Guimarães Orientadora: Prof. Dra. Sely Maria de Souza Costa 


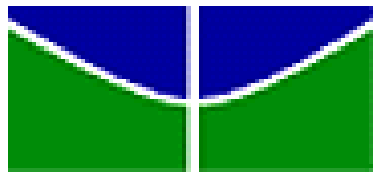

Universidade de Brasília (UnB)

Faculdade de Ciência da Informação ( $\mathrm{FCl}$ )

Curso de Biblioteconomia

\section{LUISA VERAS DE SANDES GUIMARÃES}

\section{QUALIDADE DE PERIÓDICOS CIENTÍFICOS BRASILEIROS QUE UTILIZAM O SISTEMA ELETRÔNICO DE EDITORAÇÃO DE REVISTAS (SEER)}

Monografia apresentada à Faculdade de Ciência da Informação da Universidade de Brasília como requisito parcial para obtenção do grau de Bacharel em Biblioteconomia.

Orientadora: Profa. Dra. Sely Maria de Souza Costa. 
Guimarães, Luisa Veras de Sandes

Qualidade de periódicos científicos brasileiros que utilizam o Sistema Eletrônico de Editoração de Revistas (SEER) / Luisa Veras de Sandes Guimarães. - Brasília, 2010.

$63 \mathrm{f} . ; 32 \mathrm{~cm}$.

Monografia apresentada à Faculdade de Ciência da Informação da Universidade de Brasília como requisito parcial para obtenção do grau de bacharel em Biblioteconomia.

Orientadora: Sely Maria de Souza Costa

Banca examinadora: Fernando César Lima Leite, Fernanda Moreno.

Bibliografia

1. Periódicos eletrônicos 2. Qualidade de periódicos 3. Acesso aberto à informação científica 4. Sistema Eletrônico de Editoração de Revistas, SEER I. Título. 
UNIVERSIDADE DE BRASÍLIA (UnB)

Faculdade de Ciência da Informação (FCl)

Curso de Biblioteconomia

\section{Aluna: Luisa Veras de Sandes Guimarães}

Monografia: Qualidade de periódicos científicos brasileiros que utilizam o Sistema Eletrônico de Editoração de Revistas (SEER). Apresentada a Faculdade de Ciência da Informação da Universidade de Brasília, como requisito parcial para obtenção do grau de Bacharel em Biblioteconomia.

Brasília, 1ํ de setembro de 2010.

Aprovada por:

Sely Maria de Souza Costa - Orientadora

Professora da Faculdade de Ciência da Informaç̧ão (FCl)

PhD em Ciência da Informação (Loughborough University)

Fernando César Lima Leite - Membro

Doutorando em Ciência da Informação 
Dedico este trabalho aos meus pais que me ajudaram em todos os momentos da vida e me guiaram para encontrar a felicidade e meu caminho profissional. 


\section{AGRADECIMENTO}

Aos meus pais Ceres e Tomás que, com muito carinho, apoio e atenção, não mediram esforços para que eu chegasse até esta etapa de minha vida.

Às minhas irmãs, Tatiara e Andressa, pelo carinho e força que me dão e por estarmos sempre juntas nos momentos mais importantes.

Aos amigos e colegas, em especial, Alessandra, Wander, Rafaella, Marjorie, Juliana, Diego, Fábio, Vanessa e Suellen. Agradeço pelo convívio, apoio, compreensão e amizade.

À professora Sely pela paciência na orientação e incentivo que tornaram possível a conclusão desta monografia.

Agradeço ao meu amigo José Alves Neto, que me motivou na escolha do curso de Biblioteconomia e me introduziu no mundo da leitura e do amor aos livros.

Agradeço a todos que, de alguma forma passaram pela minha vida e contribuíram para a construção de quem sou hoje. 
Escolhe um trabalho de que gostes, e não terás que trabalhar nem um dia na tua vida. (Confúcio)

Os investimentos em conhecimento geram os melhores dividendos. (Benjamin Franklin) 


\section{RESUMO}

Visou-se com este estudo analisar a qualidade de periódicos científicos eletrônicos brasileiros que utilizam o Sistema Eletrônico de Editoração de Revistas (SEER). Para tanto, buscou-se na literatura os principais critérios para avaliar a qualidade, selecionando-se aqueles considerados de maior relevância. $O$ universo da pesquisa é constituído de periódicos que estavam cadastrados em suas áreas do conhecimento no endereço eletrônico do sistema, no Portal do lbict, em junho de 2010, totalizando 236. A amostra é de caráter intencional e de acordo com os critérios estabelecidos foram selecionados 78 periódicos para o estudo. Os aspectos de qualidade avaliados foram: corpo editorial, autores, regras de submissão de artigos, arbitragem por pares, idade, formato, idioma de publicação e impacto dos periódicos. Os resultados permitem afirmar que os periódicos estudados atenderam de forma adequada aos critérios estabelecidos para o estudo.

Palavras-chave: Periódico Científico Eletrônico. Acesso Aberto à Literatura Científica. Sistema Eletrônico de Editoração de Revistas (SEER). Qualidade de periódicos. 


\begin{abstract}
This study aimed to assess whether Brazilian journals that use the Open Journal Systems (OJS) for publishing comply with quality requirements necessary to scientific journals. To this end, it was necessary to search in literature the main criteria for evaluating quality, selecting those considered most relevant. The universe of the research was comprised of 236 journals (the ones that were correctly registered in their knowledge area in the system Web site by June 2010). The sample's nature is intentional and, according to the established criteria, 78 journals were selected for the study. The quality aspects evaluated were: editorial board, authors, rules for article submission, peer review, age, format, language of publication and journals impact. The results indicate that the studied journals adequately met the criteria established for the research.
\end{abstract}

Keywords: Scholarly and Scientific Electronic Journals. Open Access to Scientific Literature. Open Journal Systems (OJS). Journals Quality. 


\section{LISTA DE GRÁFICOS}

Gráfico 1 - Titulação, Afiliação e Nacionalidade dos membros do Corpo Editorial ...39

Gráfico 2 - Produtividade do Corpo Editorial .........................................................39

Gráfico 3 - Afiliação e Nacionalidade dos autores .................................................41

Gráfico 4 - Divisão dos periódicos da amostra por área do conhecimento................43

Gráfico 5 - Idade dos periódicos ..........................................................................

Gráfico 6 - Correlação do índice H com a idade dos periódicos ..............................45

Gráfico 7 - Idioma de publicação dos artigos.......................................................46

Gráfico 8 - Formato dos periódicos …………….............................................

Gráfico 9 - Apresentação das regras de Formatação e Normalização ........................48

Gráfico 10 - Apresentação dos critérios de avaliação ............................................50

Gráfico 11 - Apresentação das datas do processo de arbitragem .............................50

Gráfico 12 - Percentual de trabalhos inéditos dos periódicos...................................51

Gráfico 13 - Índice H dos periódicos estudados ................................................52 


\section{LISTA DE ABREVIATURAS E SIGLAS}

ABEC Associação Brasileira de Editores Científicos

ABNT Associação Brasileira de Normas Técnicas

CAPES Coordenação de Aperfeiçoamento do Pessoal do Ensino Superior

CNPq Conselho Nacional de Desenvolvimento Científico e Tecnológico

EnANPAD Encontro da Associação Nacional de Pós-Graduação e Pesquisa em Administração

Fapesp Fundação de Amparo à Pesquisa do Estado de São Paulo

Finep Financiadora de Estudos e Projetos

Ibict Instituto Brasileiro de Informação em Ciência e Tecnologia

ISI Institute for Scientific Information

ISSN International Standard Serial Number

JCR Journal of Citations Report

LOCKSS Lots of Copies Keeps Stuff Safe

OAI Open Archives Initiative

OJS Open Journal Systems

SEER Sistema Eletrônico de Editoração de Revistas

TICs Tecnologias da Informação e Comunicação

UNESCO Organização das Nações Unidas para Educação, Ciência e Cultura 


\section{SUMÁRIO}

1 INTRODUÇÃO

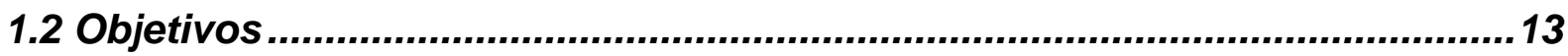

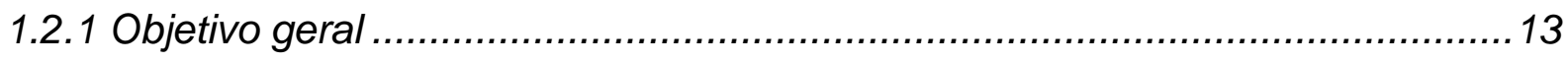

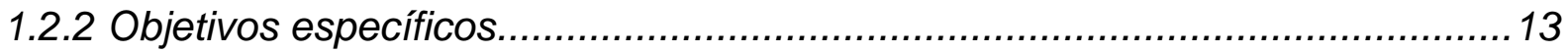

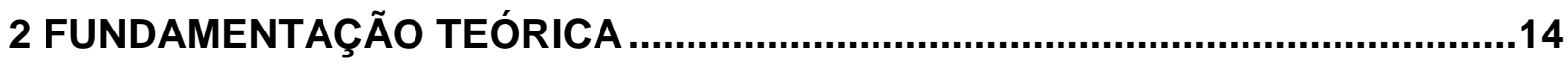

2.1 Tecnologias da Informação e Comunicação e Periódicos Científicos ..........14

2.20 movimento de acesso aberto à literatura científica...................................17

2.3 A qualidade de Periódicos Científicos .....................................................20

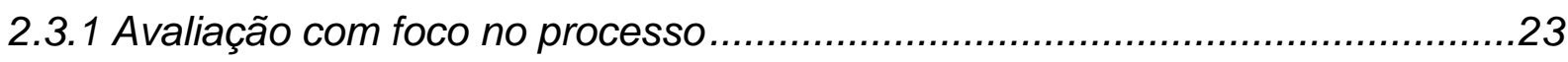

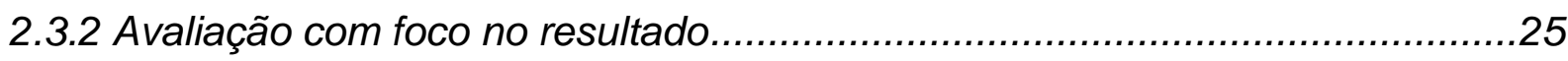

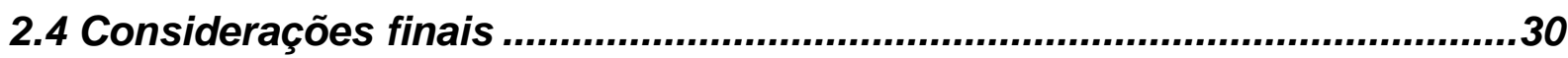

3 METODOLOGIA

3.1 Universo

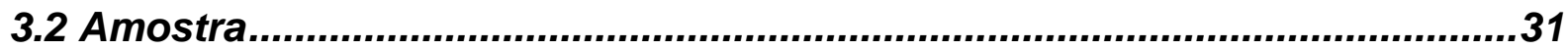

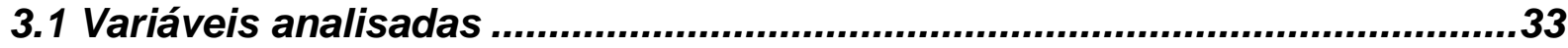

4 RESULTADOS E DISCUSSÃO

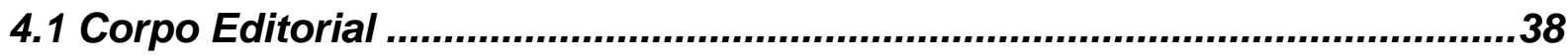

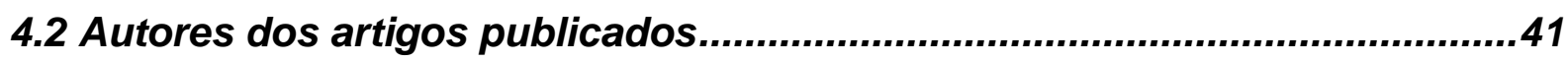

4.3 Dados gerais dos periódicos estudados.......................................................42

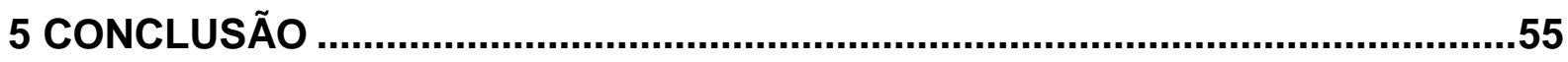

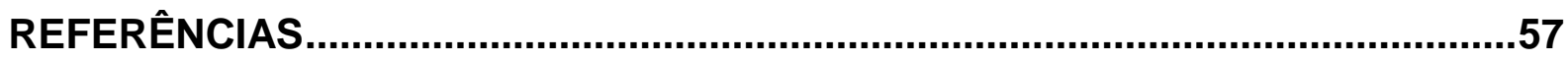




\section{INTRODUÇÃO}

Um dos canais mais utilizados para a comunicação científica é o periódico. Segundo Meadows (1999), o principal motivo para o surgimento do periódico científico foi a necessidade de uma comunicação mais eficiente entre pesquisadores. Tenopir e King (2001) mostram que artigos publicados em periódicos constituem o mais importante recurso informacional utilizado por cientistas em seu trabalho, tanto na atividade de docência quanto na de pesquisa.

É importante observar que, para que os resultados do trabalho de pesquisa sejam considerados como conhecimento científico, estes devem ser avaliados por pares e, posteriormente, publicados em um periódico científico, livro ou outros meios.

No entanto, no que concerne aos periódicos, o preço de assinatura aumentou substancialmente ao longo das últimas décadas e o orçamento de grande maioria das bibliotecas, não. Isso impossibilitou bibliotecas de manterem o mesmo número de assinaturas de periódicos e criou uma barreira de acesso aos conteúdos de conhecimentos que são divulgados (KING; TENOPIR, 1998).

Tal contexto coincide com o desenvolvimento das tecnologias da informação e comunicação, na segunda metade do século XX. Começam a surgir os periódicos eletrônicos, que tornam a publicação dos resultados de pesquisas mais ágil e dinâmica. Um dos impactos mais recentes das tecnologias de informação na comunicação científica está relacionado à questão do acesso aberto a essa literatura.

Alberts (2002) salienta que como as pesquisas científicas são financiadas basicamente com recursos públicos, seus resultados, o conhecimento científico, devem ser reconhecidos como um bem público global e estar livremente acessível a todos. Também é necessário considerar o fato de que o desejo da grande maioria dos pesquisadores não é o retorno financeiro, mas sim a ampla difusão de seus trabalhos, para que possam ganhar mais visibilidade dentro da comunidade científica (HARNARD, 1995). 
Tal situação propiciou o surgimento de um movimento na comunidade científica em favor do acesso aberto à informação. A iniciativa definiu duas estratégias para possibilitar o acesso aberto. Harnard et al. (2004) as chamaram de a "via verde" (o auto-arquivamento em repositórios de acesso aberto) e "via dourada" (os periódicos eletrônicos de acesso aberto).

Uma importante iniciativa brasileira visando ao acesso aberto foi a adoção, por parte do Instituto Brasileiro de Informação em Ciência e Tecnologia (Ibict), do Sistema Eletrônico de Editoração de Revistas (SEER). Este é a customização do software Open Journal Systems (OJS) e tem por objetivo a construção e o gerenciamento de todas as etapas de editoração de um periódico eletrônico (MÁRDERO ARELLANO; SANTOS; FONSECA, 2005).

O problema, no entanto, é que a criação e edição de periódicos com o uso deste sistema vêm crescendo bastante desde seu surgimento. O uso do SEER no Brasil tinha permitido a criação de 300 títulos até março de 2008. Em junho de 2010 o número de títulos havia aumentado em $160 \%$, totalizando 780 periódicos. A liberdade e facilidade de uso do sistema podem levar a não observância das questões relevantes sobre qualidade de periódicos científicos.

A pergunta, portanto, que esta pesquisa visou responder foi: A qualidade de periódicos científicos brasileiros que utilizam o SEER corresponde aos critérios que devem ser levados em consideração na criação e manutenção de periódicos científicos eletrônicos?

A relevância deste estudo reside no seu potencial de criação de conhecimento em área pouco explorada na literatura e por oferecer sugestões que podem servir de base para alterar políticas de editoração de periódicos científicos no Brasil. 


\subsection{Objetivos}

\subsubsection{Objetivo geral}

Verificar se periódicos brasileiros que utilizam o Sistema Eletrônico de Editoração de Revistas (SEER) cumprem os requisitos identificados na literatura como necessários para periódicos científicos de qualidade.

\subsubsection{Objetivos específicos}

- Identificar o contexto no qual se inserem os periódicos científicos eletrônicos;

- Identificar, na literatura, os critérios normalmente utilizados na avaliação de periódicos científicos;

- Descrever os aspectos essenciais a serem considerados por editores para criação e manutenção de periódicos de qualidade;

- Avaliar se periódicos que utilizam o SEER possuem qualidade científica. 


\section{FUNDAMENTAÇÃO TEÓRICA}

\subsection{Tecnologias da Informação e Comunicação e Periódicos Científicos}

As tecnologias da informação e comunicação (TICs) desenvolveram-se na segunda metade do século $X X$, no contexto da assim chamada explosão informacional. Com o passar do tempo, a comunicação eletrônica passou a ser amplamente utilizada por pesquisadores para disseminação de suas pesquisas, dada sua rapidez e à possibilidade de interatividade. Garvey e Grifith (1979) fizeram um estudo com pesquisadores da área de psicologia e apresentaram um modelo de comunicação científica para esta área, baseado no meio impresso. O modelo apresenta o processo que envolve a comunicação científica, desde o início da pesquisa, passando pela apresentação dos resultados em conferências, pelo envio para avaliação, pela publicação e, finalmente, a utilização dos resultados.

Com o surgimento do meio eletrônico, o modelo de Garvey e Grifith sofreu adaptações. Hurd (1996) fez um estudo com cientistas naturais e apresentou um modelo inteiramente baseado no meio eletrônico. Percebe-se, no modelo da autora, que o tempo despendido nas etapas entre o início da pesquisa e a publicação e disseminação de seus resultados diminui consideravelmente. Costa (1999), ao estudar os cientistas sociais, adaptou o trabalho de Hurd e propôs um modelo híbrido para a comunicação em que se verifica a coexistência do meio impresso e do meio eletrônico. Readaptando seu modelo, Costa (2006) apresentou um novo modelo, no qual procura representar o momento atual e mostrar o quanto o meio impresso e o meio eletrônico se encontram presentes em cada etapa do processo de comunicação científica.

Segundo Costa (2006) apesar dessas mudanças na comunicação científica, duas questões permanecem inalteradas. A primeira é a predominância do uso do meio eletrônico nas etapas do processo em que ocorre a comunicação informal. A segunda é a tendência de cientistas das áreas exatas e naturais utilizarem mais a comunicação por meio eletrônico do que os cientistas sociais e humanistas. Moreno e Márdero Arellano (2005) acrescentam que a comunicação eletrônica permite a transmissão de conhecimentos de forma ágil, a baixo custo e com a possibilidade de 
maior interação entre os pesquisadores. No contexto atual, as questões mais discutidas sobre as TICs na comunicação científica dizem respeito aos arquivos abertos, os quais têm modificado significativamente a publicação científica.

Lagoze e Van de Sompel (2001) explicam que no termo Arquivo Aberto, a palavra arquivo é utilizada em um sentido mais amplo, significando um repositório para armazenar informações. A palavra aberto, por seu turno, refere-se à arquitetura do sistema, a qual promove uma interface de máquina que facilita a disponibilidade de conteúdos de diversos fornecedores. A origem dos Arquivos Abertos está associada a problemas e insatisfações com o sistema de publicação científica tradicional.

Segundo Branin e Case (1998), o sistema de publicação científica é composto de três principais componentes: os cientistas (autores das pesquisas), os editores e os bibliotecários. Harnard (1995) chama a atenção para o fato de que os interesses de autores e editores são divergentes. Os primeiros desejam a difusão livre e rápida dos seus trabalhos, para serem reconhecidos, enquanto os últimos buscam obter benefícios financeiros, restringindo o acesso à informação a quem pode pagar.

Nesse contexto, Lagoze e Van de Sompel (2000) chamam especial atenção para a questão da "crise dos periódicos". Para os autores, tal crise ocorre primordialmente nas bibliotecas de pesquisa, as quais não possuem fundos suficientes para manter as assinaturas dos principais periódicos, visto que o preço destes aumenta cada vez mais. Sobre a questão dos custos envolvidos na publicação de periódicos científicos, King e Tenopir (1998) ressaltam quatro aspectos: processamento de artigos, impressão e distribuição, processamento de outras matérias que não são artigos, e serviços de apoio à publicação. De fato, um número variado de estudos reforça a questão dos altos custos dos periódicos nas últimas décadas.

É nesse contexto, portanto, que surgem os primeiros Arquivos Abertos. O arXiv foi o pioneiro dessas iniciativas, implementado em 1991, por Paul Ginsparg, do Laboratório Nacional de Los Alamos nos EUA como um repositório que abriga artigos da área da física, matemática e ciência da computação. Outros repositórios 
foram criados posteriormente em outras áreas do conhecimento. Do mesmo modo, outras formas de publicação e acesso à pesquisa, como os periódicos eletrônicos e os repositórios institucionais, também foram desenvolvidas e passaram a adotar as especificações definidas pela Open Archives Initiative (OAl), i.e., padrões para garantir a interoperabilidade entre os sistemas (LAGOZE; VAN DE SOMPEL, 2000).

No que concerne aos periódicos, Lancaster (1995) considera que a primeira experiência com periódico eletrônico foi em 1979, pelo Electronic Information Exchange System. No ano seguinte, a British Library financiou a Loughborough University para estabelecer um periódico experimental online na área de fatores humanos na computação. Esses primeiros experimentos não tiveram muito sucesso e foram descontinuados. Ainda segundo o autor, os periódicos científicos em formato eletrônico apresentam inúmeras vantagens ao formato impresso, como rapidez na publicação e acesso. Entretanto, cabe lembrar que muitas pessoas ainda não têm acesso ao computador e à Internet, e alguns acham incômodo ler na tela do computador.

De acordo com Stumpf (1996), a partir da década de 70, o uso do computador provocou avanços, viabilizando a melhoria da qualidade e aumentando a rapidez na editoração. O projeto BLEND, desenvolvido na década de 80 pelas Universidades de Birmingham e Loughborough e financiado pela British Library, procurou avançar mais na produção dos periódicos. Visou não somente automatizar todas as etapas do processo, mas substituir totalmente a publicação impressa pela armazenagem eletrônica dos artigos e, em conseqüência, seu acesso (STUMPF, 1996).

Há, contudo, uma gama de questões que necessitam de maior discussão nesse contexto. Harnard (1995), por exemplo, ressalta que nas publicações eletrônicas, é possível uma economia de $70 \%$, pois não há custos com papel, impressão, marketing e distribuição para os periódicos que são somente eletrônicos. Somente duas categorias de custo permanecem: a avaliação e a editoração. Moreno e Márdero Arellano (2005) afirmam que, embora seja necessário um investimento inicial para mudar para uma versão eletrônica, ao longo do tempo os custos diminuem. 
Analisando questões do periódico eletrônico, Mueller (2003) destaca problemas de confiança e acesso, decorrentes dos hábitos da comunidade científica e dos interesses de editoras comerciais. Meadows (1999) havia destacado, também, que o formato online pode parecer mais informal, dando a impressão de que o controle poderá ser menos prudente do que o das publicações impressas no que se refere à qualidade da pesquisa.

Entretanto, esta preocupação que Meadows (1999) destaca diminui ao longo do tempo, já que muitos periódicos consolidados no meio impresso possuem também a versão eletrônica. Mueller (2003) também ressalta que com o aumento do número de periódicos eletrônicos com qualidade científica, ocorre um conseqüente aumento na aceitação por parte dos cientistas.

O crescimento nas ocorrências de periódicos científicos eletrônicos fez surgirem novas preocupações e iniciativas, resultantes das vantagens oferecidas pelo uso de tecnologias de informação e comunicação. A principal iniciativa, e também a mais polêmica, é o movimento mundial em favor do acesso aberto, discutido a seguir.

\subsection{0 movimento de acesso aberto à literatura científica}

O movimento em favor do acesso aberto à literatura científica surgiu devido a alguns fatores. Segundo Suber (2003), além da questão da crise de preço dos periódicos, é também relevante considerar o problema das barreiras de permissão. Harnard et al. (2004) acrescentam a questão da perda do potencial impacto das pesquisas. Os autores destacam que existem cerca de 24.000 periódicos com mecanismo de avaliação por pares no mundo, publicando aproximadamente 2,5 milhões de artigos por ano.

Em razão de barreiras impostas por custos cada vez mais altos, os usuários têm acesso cada vez mais limitado a periódicos científicos, perdendo-se muito do potencial impacto de artigos com acesso pago. Na medida em que o impacto é crucial para a carreira dos pesquisadores, pois mede o progresso e a produtividade da pesquisa e serve como meio para obter benefícios de suas universidades e das agências de fomento (HARNARD et al., 2004), quanto maior o impacto, melhor para 
a ciência e para a comunidade científica. Por esse motivo é relevante o movimento em favor do acesso aberto.

É importante lembrar que as primeiras ações em direção ao acesso aberto (Budapest Open Access Initiative (2002) e Bethesda Statement on Open Access Publishing (2003)) apontaram para o estabelecimento de duas estratégias para o acesso aberto, ambas em conformidade com a Iniciativa de Arquivos Abertos.

A primeira, o auto-arquivamento (autores depositam, em um repositório de acesso aberto, seus artigos publicados ou aceitos para publicação em algum periódico referendado); Harnard et al. (2004) chamam esta estratégia de Via Verde, pois os editores dão sinal verde para o auto-arquivamento de artigos por parte dos autores.

A segunda, os periódicos de acesso aberto, chamados por Harnard et al. (2004) de Via Dourada, pois os editores garantem o acesso aberto aos conteúdos dos próprios periódicos. O acesso aberto, nos dizeres da iniciativa, portanto, é a disponibilidade livre e irrestrita, em meio eletrônico, da literatura que os pesquisadores entregam ao mundo sem esperar pagamento em retorno (incluem tanto os pós-prints quanto os pré-prints).

Um resultado importante dessas ações é a declaração de Bethesda (2003), estabelecendo que:

a. O autor e o detentor do copyright garantem a todos os usuários um livre, irrevogável, mundial e perpétuo direito de acesso aos seus trabalhos; licença para copiar, usar, distribuir, transmitir e exibir o trabalho publicamente; para fazer e distribuir trabalhos derivados, em qualquer meio digital para qualquer propósito responsável, sujeito à atribuição correta de autoria, assim como o direito de fazer um pequeno número de cópias para uso pessoal.

b. Uma versão completa do trabalho e todos os materiais suplementares, incluindo uma cópia da permissão citada anteriormente, em formato eletrônico, deve ser depositada, logo após a publicação, em 
um repositório mantido por uma instituição acadêmica, sociedade científica, agência governamental ou outra instituição que deseje permitir o acesso aberto.

Essas e outras iniciativas deram impulso ao movimento pelo acesso aberto, causando certa pressão nas editoras que continuam detendo o copyright e impondo altos preços para as assinaturas. A questão relevante, no entanto, que é o acesso e o conseqüente impacto das pesquisas, tem sido o grande debate nos dias atuais. $O$ aumento do impacto pode ser comprovado, de fato, por estudos realizados nos últimos anos.

Lawrence (2001), analisando artigos da área de ciência da computação, mostra que ocorrem 336\% mais citações aos artigos que estão disponíveis online em comparação aos artigos publicados off-line. Antelman (2004) verificou que, mesmo em disciplinas de diferentes áreas do conhecimento (filosofia, ciência política, engenharia elétrica e eletrônica e matemática), o impacto é maior para os artigos que tem acesso aberto, apesar de haver algumas diferenças entre as disciplinas.

Um último, mas não menos importante aspecto sobre o acesso aberto e os periódicos científicos eletrônicos é o surgimento de novos e diversificados modelos de negócios para os periódicos disponíveis em acesso aberto. Tais modelos, como os dez propostos por Wilinsky (2006), surgem como alternativa ao modelo tradicional das editoras comerciais. A preocupação com essa questão levou ao surgimento de várias iniciativas, entre elas a criação do Open Journal Systems (OJS), pelo Public Knowledge Project, da Universidade de British Columbia, do Canadá, discutido a seguir.

De acordo com Meirelles (2006), os sistemas de gerenciamento de periódicos eletrônicos surgiram como uma tentativa de organizar a informação da Internet e de administrar as atividades do processo editorial. Isso ocorreu devido ao movimento de Acesso Aberto e à iniciativa dos Arquivos Abertos. Fonseca et al (2004) destacam que os periódicos de acesso aberto são uma tendência cada vez mais crescente no ambiente científico. Os autores afirmam que a escolha por um instrumento que automatiza o processo editorial utilizando padrões e tecnologias 
baseados na filosofia do acesso aberto torna-se uma solução alternativa à escassez de recursos. Além disso, estimula a democratização do acesso à informação, tornando o conteúdo disponível e favorecendo a interoperabilidade com "provedores de serviço nacionais e internacionais".

Segundo Márdero Arellano, Santos e Fonseca (2005), o OJS destaca-se entre os sistemas para a publicação e disseminação da produção científica de suporte ao acesso aberto. O OJS é um software que contém os elementos essenciais para a automação das atividades de editoração de periódicos científicos, desde a submissão e avaliação de um manuscrito até a sua publicação e indexação.

Em 2003, o Instituto Brasileiro de Informação em Ciência e Tecnologia (lbict) traduziu e customizou o OJS para a realidade das revistas brasileiras, que passou a ter o nome de Sistema Eletrônico de Editoração de Revistas (SEER). Ainda segundo os mesmos autores, o SEER utiliza o protocolo OAI para o intercâmbio de metadados. Além disso, possui suporte para mecanismos de preservação do seu conteúdo (como o LOCKSS - Lots of Copies Keep Stuff Safe), sendo, assim, uma ferramenta de apoio à pesquisa.

\subsection{A qualidade de Periódicos Científicos}

A avaliação da qualidade de periódicos científicos não é assunto novo no meio acadêmico. No ano de 1964, por exemplo, a Organização das Nações Unidas para Educação, Ciência e Cultura (UNESCO) elaborou um modelo para avaliar periódicos Latino-Americanos, o qual serviu como base para grande parte das avaliações e modelos surgidos posteriormente.

Ferreira e Krzyzanowski (2003) listam alguns dos primeiros trabalhos sobre o assunto, descritos resumidamente a seguir:

* 1968 - Arends baseia-se no modelo criado pela UNESCO em 1964 e propõe a avaliação de critérios relacionados a: apresentação do material; regularidade da publicação; tempo de existência; periodicidade; receptividade a colaboradores de outras instituições; indexação e outros. 
* 1982 - Braga e Oberhofer propõem um modelo, baseado no da UNESCO, onde se avaliam critérios de normalização, periodicidade, indexação, difusão, autoridade e outros. Os critérios apresentam diversas variáveis e cada uma possui uma pontuação. De acordo com o número de pontos acumulados, atribuiu-se um nível de desempenho aos periódicos (muito bom, bom, mediano e fraco).

* 1985 - Yahn, avaliando periódicos da área de Agricultura, modifica o modelo de Braga e Oberhofer acrescentando a avaliação do conteúdo dos artigos, juntamente com a avaliação de forma.

* 1986 - Martins realiza uma avaliação com o intuito verificar, em 224 periódicos da área de Ciência e Tecnologia, a conformidade destes com os itens referentes à normalização descritos nas normas da Associação Brasileira de Normas Técnicas (ABNT).

Esses trabalhos foram essenciais para alertar a comunidade científica para a qualidade de periódicos. Posteriormente, outros autores modificaram ou criaram novos critérios que complementam a literatura da área e se adaptam aos novos padrões e mudanças do século XXI.

Stumpf (2003) realizou um estudo com 26 periódicos da área de Comunicação onde, com a colaboração de docentes e pesquisadores da área, avaliou os periódicos de acordo com os critérios a seguir: "qualidade da revista; prestígio da revista junto à comunidade; qualidade dos artigos publicados; contribuição da revista para a área; rigor na avaliação dos artigos; regularidade da publicação; apresentação gráfica e distribuição." Cada pesquisador ou docente atribuiria uma nota de 1 a 5 para os itens de avaliação.

Ferreira et al. (2009) avaliaram periódicos científicos eletrônicos na área de Direito, especificamente, periódicos na plataforma SEER e com conceito Qualis A ou B. A avaliação foi feita com base em critérios de normalização, periodicidade, indexação e navegação. Os periódicos foram pontuados e classificados de acordo com o desempenho (de "Fraco" a "Muito bom"). 
Trzesniak (2006) acredita que foi com a criação e desenvolvimento da base Qualis, mantida pela Coordenação de Aperfeiçoamento do Pessoal do Ensino Superior (CAPES), que o processo de avaliação tornou-se mais conhecido e mais considerado por pesquisadores de diversas áreas. O Qualis avalia a qualidade dos periódicos atribuindo uma das classificações a seguir: A1 (maior); A2; B1; B2; B3; B4; B5 e C (menor).

Nas palavras de Trzesniak (2006, p. 347): "Atualmente, é incomum um pesquisador, ao encaminhar um artigo, não levar em conta a classificação Qualis do periódico. É cada vez mais comum ele se interessar acerca de como a avaliação Qualis é feita e em que critérios ela se baseia."

Consequentemente, os editores passaram a ter uma preocupação maior com aspectos formais de um periódico científico, levados em consideração na avaliação de qualidade, tais como: International Standard Serial Number (ISSN), normas para publicação, instruções aos autores, regularidade e periodicidade da publicação. Além dos aspectos formais, Yamamoto e Costa (2009, p. 196) acreditam que:

[...] a avaliação induziu os editores a buscarem qualificar os periódicos sob sua responsabilidade do ponto de vista do conteúdo. Indicadores indiretos são a valorização de um sistema mais transparente e qualificado de arbitragem (com descrições do processo, nominatas de conselheiros e consultores), a abertura para instituições diversas daquela de origem, com ênfase naquelas que estivessem em outras Unidades da Federação e, um aspecto importante, a busca pela indexação das revistas em bases consagradas.

A análise da literatura sobre qualidade de periódicos científicos permite concluir que a qualidade pode ser avaliada com foco no processo ou no resultado. Na primeira situação, consideram-se fatores relacionados com a gestão editorial, tais como, formação e expertise da equipe editorial (editores, corpo e conselho editoriais), regras de submissão e de avaliação de manuscritos, prazos de avaliação e de disponibilização de artigos aprovados, dentre outros. Na avaliação com foco no resultado, importa saber o nível de impacto que artigos publicados em um determinado periódico exercem sobre a comunidade científica e, portanto, em que medida contribuem para o crescimento de determinada área de conhecimento. 
Nessa linha, quanto mais os artigos de um periódico são citados por outros autores, maior o nível de impacto do periódico.

Essas metodologias não são excludentes, dado que um processo editorial adequado certamente contribuirá para a qualidade dos artigos publicados. Portanto, quanto maior o nível de qualidade destes, maior a probabilidade de o periódico alcançar um alto nível de impacto.

\subsubsection{Avaliação com foco no processo}

Este tipo de avaliação engloba duas dimensões da qualidade de periódicos científicos, que Trzesniak (2006) designou como qualidade da finalidade do produto e qualidade do processo produtivo. Considerando a primeira dimensão, a avaliação da qualidade normalmente analisa os seguintes itens:

\footnotetext{
a) um corpo editorial científico altamente qualificado, que cubra bem a área de abrangência temática do $p$ eriódico, que seja diversificado institucional e geograficamente (aspectos relativamente fáceis de avaliar ) e que se envolva na revisão dos "compuscritos" (o envolvimento efetivo não é fácil de avaliar...);

b) consultores ad hoc com boa qualificaçã o e com diversidade geográfica e institucional (TRZESNIAK, 2006, p. 350).
}

Para a qualidade do processo produtivo, os itens considerados na avaliação normalmente incluem: cumprimento da periodicidade (bimestral, trimestral, etc.) e; inclusão das datas de recebimento e aceitação dos artigos. Este, por sua vez, é um indício de eficiência ou morosidade no processo de avaliação dos artigos.

Além dos aspectos citados anteriormente, a avaliação com foco no processo também verifica a qualidade das instruções fornecidas aos autores. Os periódicos devem informar quais são as exigências mínimas para que o trabalho seja avaliado. Basicamente, devem explicitar: os modelos adotados de formatação e normalização (referências, citações, etc.); idioma dos trabalhos; número mínimo e máximo de páginas do trabalho e outros aspectos. Também é interessante que o periódico explique o processo de submissão de manuscritos. Além disso, é importante que o periódico informe aos autores como acontece o processo de avaliação dos trabalhos submetidos e os critérios utilizados na avaliação. 
No caso da avaliação com foco no processo, cabe citar aqui alguns trabalhos relevantes relacionados à temática. Nesse sentido, três trabalhos são destacados e apresentados cronologicamente, visando a contribuir para a discussão dos critérios de qualidade.

Krzyzanowski e Ferreira (1998) analisaram periódicos científicos e técnicos brasileiros avaliados por agências de fomento, tais como: a Fundação de Amparo à Pesquisa do Estado de São Paulo (Fapesp), Conselho Nacional de Desenvolvimento Científico e Tecnológico (CNPq) e Financiadora de Estudos e Projetos (Finep). Foram analisados critérios sobre mérito e forma. Para a avaliação de mérito foram convocados diversos pesquisadores da Fapesp de cada área do conhecimento, onde cada um teve que classificar as publicações de acordo com a relevância. Os profissionais avaliaram critérios de: qualidade da publicação (artigos, corpo editorial, arbitragem); natureza do órgão publicador; indexação. Para a avaliação de forma, foram analisados os últimos três fascículos quanto a: "normalização, duração, periodicidade, indexação de títulos em bases de dados internacionais, formas de distribuição, existência de coleção nas bibliotecas-base do Sistema Comut, colaboração de autores, divisão de conteúdo."

Os autores concluíram que as agências financiadoras poderiam instituir um método de avaliação de periódicos mais abrangente e uniforme, tal como o de conteúdo e forma, de modo a realizar um julgamento mais preciso. Sugeriram também que as agências mantenham estável o subsídio dos periódicos classificados como prioritários pertencentes a: "instituições de pesquisa, ensino e sociedades científicas".

Yamamoto et al. (2002) fizeram a avaliação de 51 periódicos da área de Psicologia que constavam nos relatórios dos programas de pós-graduação nos anos de 1999 e 2000. A avaliação foi realizada utilizando diversos critérios que foram subdivididos em cinco conjuntos (Normalização, Publicação, Circulação, Autoria e Conteúdo e Gestão editorial). Depois de realizada a avaliação, a Comissão Editorial conjunta (CAPES e ANPEPP) conferiu as fichas e gerou uma classificação considerando a Qualidade (A, B ou C) e o Âmbito (Nacional ou Local). Com os resultados obtidos, foi possível verificar que as revistas da área melhoraram sua classificação. 
Ferreira (2005), tomando como base algumas iniciativas como a SciELO, o Latinlndex e o ISCU Press, identificou os principais critérios de qualidade de revistas científicas, tanto em meio eletrônico como em meio impresso. A autora classificou esses critérios segundo quatro aspectos. $O$ primeiro diz respeito às características básicas das revistas. $\mathrm{O}$ segundo, aos aspectos referentes à apresentação formal. $\mathrm{O}$ terceiro aspecto refere-se à tipologia de conteúdos e autoria. Finalmente, são apresentados os aspectos de gestão e política editorial da revista.

\subsubsection{Avaliação com foco no resultado}

No caso da avaliação com foco no resultado, faz-se necessário estabelecer o nível de impacto de periódicos. Tal procedimento requer a organização e manutenção de bases de dados específicas, atividade até então realizada primordialmente em países desenvolvidos.

Calvert e Zengzhi (2001) acreditam que alguns critérios avaliados em periódicos são critérios basicamente extrínsecos, que poucos dos envolvidos com a publicação do periódico considerariam muito importantes para a avaliação de sua qualidade. Tais critérios seriam: composição, reputação do periódico, afiliação do Editor, reputação do Editor, Corpo Editorial, política de avaliação dos artigos e percepção do periódico. Ao invés disso, o foco deveria ser, na verdade, no conteúdo do periódico e na qualidade dos artigos publicados.

Para a avaliação de qualidade e impacto de periódicos é comum a utilização da Bibliometria. Tague-Sutcliffe (1992, p. 1) especificou o significado e as diferenças entre Bibliometria, Cienciometria e Informetria. Na visão do autor, as áreas citadas poderiam ser definidas da seguinte maneira:

[...] Bibliometria é o estudo dos aspectos quantitativos da produção, disseminação e uso da informação registrada. Desenvolve modelos matemáticos e medidas para tais processos e os utiliza para elaborar previsões e para tomada de decisões. Aparentemente, foi usada pela primeira vez por Pritchard (1969), substituindo o termo bibliografia estatística.

O termo cienciometria surgiu como o nome de um periódico criado por T. Braun em 1977, originalmente publicado na Hungria. Cienciometria é o estudo de aspectos quantitativos da ciência enquanto disciplina ou atividade econômica. Faz parte da sociologia da ciência e possui aplicações no desenvolvimento de políticas 
científicas. Envolve estudos quantitativos de atividades científicas, incluindo, entre outros, publicação e, portanto, sobrepõe-se à bibliometria.

Informetria é o estudo de aspectos quantitativos da informação em qualquer forma, não somente registros bibliográficos, e em qualquer grupo social, e não somente cientistas. Portanto, observa os aspectos quantitativos da comunicação informal e oral, como também da registrada, e observa o uso e a necessidade de informações dos mais desprivilegiados, e não apenas da elite intelectual. A informetria pode incorporar, utilizar e estender seus muitos estudos de mensuração da informação que se encontram fora dos limites da bibliometria e cienciometria [Tradução da autora].

De acordo com o autor, a bibliometria e a cienciometria realizam seus estudos em determinadas áreas, tais como:

1. Aspectos estatísticos da linguagem, palavra e frequência de frases, nos textos em linguagem natural ou em índices, em mídia eletrônica ou impressa;

2. Características dos autores: produtividade calculada pelo número de artigos ou outros meios, grau de colaboração;

3. Características das fontes de publicação, notadamente, a distribuição dos artigos de uma área nos periódicos;

4. Análise de citações: distribuição sobre autores, artigos, instituições, periódicos, países; uso na avaliação;

5. Uso de informação registrada: circulação na biblioteca e uso interno de livros e periódicos, uso das bases de dados;

6. Obsolescência da literatura, calculada por meio do uso e da citação;

7. Crescimento da literatura de uma área, bases de dados, bibliotecas, crescimento concomitante de novos conceitos.

Um exemplo de estudo bibliométrico recente, envolvendo a análise de citações é o de Machado-da-Silva et al. (2008). Os autores avaliaram periódicos científicos brasileiros na área de Administração, utilizando-se do fator de impacto relacionado com a classificação desses periódicos no Qualis da CAPES. Analisaram, durante o período de 2005 a 2007, 21 periódicos e anais do Encontro da Associação Nacional de Pós-Graduação e Pesquisa em Administração (EnANPAD), efetuando uma divisão dos periódicos em três grupos. 'A' Nacional Antigos (que já 
apresentam a nota de avaliação ' $A$ ' há algum tempo); 'A' Nacional Recentes (nota da avaliação de 2007); 'B' Nacional.

Os autores verificaram que as citações e o fator de impacto são maiores no grupo 'A' Nacional Antigos. Quanto aos dois outros grupos, não houve diferença significativa entre os fatores de impacto de ambos. Além disso, verificaram que não há influência expressiva das autocitações no cálculo do fator de impacto. Ainda segundo esses autores, a pesquisa permitiu concluir que o fator de impacto é um critério viável e relevante na avaliação de periódicos. Isso não significa que somente esse critério deva ser utilizado, mas sim reconhecê-lo como importante, podendo ser utilizado em conjunto com outros.

Mugnaini e Strehl (2008) comentam que há pouco tempo atrás, os únicos dados que forneciam uma noção do impacto das publicações científicas eram gerados a partir das bases de dados contidas no Web of Science, compiladas pelo Institute for Scientific Information (ISI). Com o passar dos anos, surgiram outras bases de dados que também fazem a indexação de citações, tais como SciELO, Scopus e Google Acadêmico. Assim o ISI vai dividindo espaço com outros serviços de indexação, pois não é mais o único mecanismo utilizado para calcular o impacto da produção científica.

O ISI publica anualmente o Journal of Citations Report (JCR), que contém três indicadores sobre os periódicos indexados nas suas bases: o Fator de Impacto, a Meia-Vida das Citações e o índice de Citação Imediata. O indicador mais utilizado em meio acadêmico é o Fator de Impacto, empregado principalmente na avaliação do desempenho de periódicos para diversas finalidades (MUGNAINI; STREHL, 2008).

Cabe ressaltar que, para determinar o Fator de Impacto de um periódico, é necessário calcular a razão entre:

1. o número de citações feitas no corrente ano a itens publicados nesse periódico nos últimos dois anos;

2. o número de artigos publicados pelo periódico nos mesmos dois anos 
De acordo com Mugnaini e Strehl (2008, p. 96-97):

Para fins de avaliação, o FI é utilizado para dedução da qualidade de um determinado artigo a partir dos valores do indicador observados para 0 periódico que o publicou. Seguindo essa lógica, um trabalho publicado em um título com alto Fl é considerado melhor do que uma pesquisa publicada em um periódico que obteve um FI menor. [...] As evidências comprovam que a utilização do indicador, de modo não contextualizado e relativizado, pode resultar no estabelecimento de critérios de avaliação injustos.

Existem algumas desvantagens na utilização do Fator de Impacto na avaliação da comunicação científica. Primeiramente, o Web of Science busca somente citações a artigos publicados nos periódicos indexados no ISI. Portanto, deixa de incluir citações a livros, capítulos de livros, dissertações, teses, relatórios, anais de congressos, e artigos publicados em periódicos não indexados no ISI (HARZING, 2007).

Outra desvantagem é que o Web of Science inclui um número muito limitado de periódicos que publicam em línguas diversas do inglês, portanto, citações a periódicos não publicados em inglês não são em geral incluídos na análise de citações do Web of Science. Supondo que os pesquisadores com muitas citações têm significativo impacto na área, e que os pouco citados têm pouco impacto na área, pesquisadores que não publicam primordialmente em inglês podem ser prejudicados (HARZING, 2007). Além disso, o acesso à base Web of Science não é gratuito. Somente instituições que pagam uma taxa de assinatura conseguem acessar os artigos e os índices disponíveis nesta base, o que limita o alcance e acesso aos artigos disponíveis.

Mugnani e Strehl (2008) ressaltam que a utilização do Fator de Impacto para avaliar a produção científica não deve ser dissociada da compreensão de fatores como:

- A obsolescência mais lenta ou mais rápida em algumas áreas do conhecimento. Como o ISI considera para a avaliação citações feitas nos dois últimos anos, áreas que tendem a citar trabalhos mais antigos tendem a ser prejudicadas;

- O padrão de citação das áreas do conhecimento. De acordo com Narin (1976), as áreas de Engenharia, Tecnologia e Matemática tendem a citar poucas referências em seus artigos, com uma média entre 5 e 6 . Psicologia 
e Biologia citam entre 8 e 10 referências por artigo. Astronomia, Física, Química e Medicina Clínica citam entre 12 e 15 referências. E finalmente, a área de pesquisa biomédica normalmente cita entre 18 e 20 referências por publicação.

Portanto, Mugnani e Strehl (2008, p. 98) concluem que "a influência dessas variáveis jamais pode ser ignorada. Isso porque diferenças de padrões de citações entre as áreas podem ser interpretadas como diferenças de qualidade entre os trabalhos".

Como exposto nos parágrafos anteriores, o uso do Fator de Impacto possui suas desvantagens. Antes, de inquestionável estima pelos pesquisadores, agora vem sendo paulatinamente substituído por outros instrumentos para avaliação do desempenho de periódicos e pesquisadores.

Um dos instrumentos com alto potencial é o Google Scholar. Em português, Google Acadêmico, esta nova ferramenta realiza de forma gratuita uma parte do trabalho que o ISI faz. Ao pesquisar artigos utilizando a ferramenta, obtêm-se o número de vezes que o artigo foi citado. Além disso, ao clicar sobre o link "Citado por ...", a ferramenta apresenta os artigos que citaram o trabalho, realizando assim, uma gama de conexões que podem ser aproveitadas por quem pesquisa certo tópico.

Ao contrário do ISI, o Google Acadêmico inclui citações a todas as publicações acadêmicas, aumentando o escopo da análise de impacto. Além disso, inclui um número bem maior de publicações em outras línguas.

Harzing (2007) ressalta que o Google Acadêmico inclui citações que não são acadêmicas, como manuais estudantis, guias de bibliotecas e notas editoriais. De qualquer modo, problemas incidentais como estes, provavelmente não distorcerão os índices de citação, já que em geral, as citações que os autores recebem advêm primordialmente de publicações científicas.

Outro problema do Google Acadêmico é que nem todos os periódicos estão indexados nesta base. A questão neste caso é que alguns dos editores comerciais não permitem que o Google indexe os periódicos que publicam, nem mesmo o título 
e o resumo dos artigos. Algumas citações também são perdidas, já que muitos periódicos são pagos e exigem assinatura para visualizar os artigos e, consequentemente, obter as citações neles contidas (HARZING, 2007).

\subsection{Considerações finais}

Como se pode observar, a inserção de tecnologias de informação e comunicação no ambiente da pesquisa provocou impactos no sistema de comunicação científica. Em especial, cientistas e pesquisadores passaram a utilizar o meio eletrônico para publicar seus resultados. Isso por sua vez, deu origem aos assim chamados periódicos científicos eletrônicos.

Mais que isso, as facilidades da comunicação eletrônica contribuíram para a identificação de alternativas à crise dos periódicos, o que, por sua vez, fez surgir o movimento do acesso aberto. Nesse contexto, a criação de ferramentas que facilitam tanto o processo de editoração de periódicos quanto a própria gestão de sua publicação, tais como o SEER, tem colaborado para fortalecer o movimento.

No entanto, a liberdade e facilidade de uso do sistema podem levar a não observância das questões relevantes sobre qualidade de periódicos científicos, tanto impressos, quanto eletrônicos. São essas, portanto, as questões que norteiam o presente estudo. 


\section{METODOLOGIA}

Visou-se com esse estudo analisar a qualidade de periódicos científicos eletrônicos brasileiros que utilizam o SEER. Para tanto, buscou-se na literatura os principais critérios para avaliar a qualidade, selecionando-se aqueles considerados de maior relevância. Trabalhou-se com indicadores de qualidade de processo e de resultado, utilizados por agências de fomento ao ensino e pesquisa do Brasil. A pesquisa é de natureza descritiva e utilizou o método de levantamento, adotando uma abordagem quantitativa.

\subsection{Universo}

O universo da pesquisa é constituído dos periódicos científicos brasileiros que utilizam o SEER e que, no momento da coleta de dados, estavam cadastrados em suas respectivas áreas do conhecimento no site do referido sistema (http://seer.ibict.br). No momento do cadastro do periódico, alguns editores não informaram a área do conhecimento a qual pertence o periódico, e, portanto, apesar de estarem acessíveis por meio do título, não foram incluídos no universo da pesquisa, pois não estavam acessíveis por área do conhecimento. Em junho de 2010, foi possível acessar 236 periódicos, cadastrados em suas áreas do conhecimento, sendo que existiam 780 periódicos no sistema. Ou seja, 544 periódicos não especificavam a área do conhecimento. Portanto, o universo considerado foi de 236 periódicos.

\subsection{Amostra}

A seleção dos periódicos para compor a amostra foi feita com base em critérios previamente estabelecidos, caracterizando uma amostra intencional. Os critérios de seleção foram os seguintes: 
a. Periódicos das áreas mais produtivas, de acordo com os indicadores de produção bibliográfica de programas de pós-graduação disponibilizados pela CAPES, referentes ao triênio 2004-2006.

b. Periódicos que iniciaram sua circulação impressa ou eletrônica em 2006, ou antes. Considerando que a coleta de dados ocorreu em 2010, estimou-se que um período de quatro anos seria um prazo razoável para o periódico se consolidar.

Ressalta-se, entretanto, que tais critérios podem levar à seleção de periódicos que possuem melhor qualidade. Mas é necessário avaliar se pelo menos tais periódicos, por pertencerem às áreas do conhecimento mais produtivas e por possuírem um tempo de vida suficiente para consolidação, apresentam o mínimo de qualidade necessária para periódicos científicos

A produtividade das áreas foi calculada pela razão entre o número de pesquisadores e o número de artigos produzidos no triênio. A partir dos índices de produtividade, calculou-se a medida que representava de maneira adequada a posição central da distribuição das áreas dentro de suas grandes áreas do conhecimento. As áreas que estivessem acima desta medida central, seriam consideradas produtivas.

Verificou-se que todas as grandes áreas do conhecimento apresentavam assimetria positiva ou negativa forte. Isso significa que a distribuição apresenta concentração em valores de grande magnitude ou pequena magnitude. Ou seja, dentro de cada grande área, existem muitas áreas com produtividade baixa ou muitas áreas com produtividade alta.

Nestes casos, a média não é a melhor medida central da distribuição. Por exemplo, se existem cinco áreas com produtividade 1 e uma com produtividade 8, a média da grande área será 2,17. Levando em conta o critério de seleção "acima da média", seriam excluídas áreas que possuem produtividade 1, pois a que possui produtividade 8 elevou o valor da média. No entanto, a seleção não representará a distribuição de maneira adequada, já que a área com produtividade 8 é uma exceção dentro da grande área do conhecimento. 
Como afirma Barbeta (1999, p. 108):

Em geral, dado um conjunto de valores, a média é a medida de posição central mais adequada, quando se supõe que estes valores tenham uma distribuição razoavelmente simétrica, enquanto que a mediana surge como alternativa para representar a posição central em distribuições muito assimétricas. A média é fortemente influenciada por valores discrepantes. [Grifo nosso]

Portanto, como a assimetria das distribuições é forte, foi escolhida a mediana para representar a posição central da distribuição, já que a média é influenciada por valores muito altos ou muito baixos. As áreas mais produtivas devem apresentar, portanto, produtividade maior que a mediana de sua grande área.

Com base nesses critérios, as áreas escolhidas foram: agronomia, ciência dos alimentos, medicina veterinária, zootecnia, biologia geral, bioquímica, ecologia, fisiologia, genética, parasitologia, zoologia, educação física, enfermagem, farmacologia, fisioterapia, medicina, nutrição, ciências atmosféricas, física, oceanografia, química, engenharia aeroespacial, engenharia civil, engenharia de materiais e metalurgia, engenharia elétrica, engenharia química, ciência da informação, comunicação, demografia, direito, economia, antropologia, ciência política, psicologia, relações internacionais, sociologia, teologia, linguagem, línguas e literatura.

Após listar os periódicos das áreas do conhecimento mais produtivas, obteve-se 184 periódicos. Desses, 84 foram excluídos por não possuírem pelo menos quatro anos de publicação, restando, portanto, 100 periódicos.

Depois de filtrar os periódicos pelo ano de início de publicação, percebeu-se que alguns periódicos apresentavam problemas, como: atrasos de um ano ou mais na publicação, problemas no acesso, e periódicos não científicos. Sendo assim, foram excluídos mais 22 periódicos, e a amostra final ficou com 78 periódicos.

\subsection{Variáveis analisadas}

As variáveis estudadas nesta pesquisa compreendem um conjunto de critérios selecionados considerados relevantes para atestar a qualidade de um 
periódico científico. Tais critérios foram identificados na literatura e compreendem fatores de qualidade das revistas, adiante indicados.

\section{Corpo Editorial}

\section{$\underline{\text { Afiliação }}$}

Refere-se ao número de pessoas com vínculo à instituição responsável pela editoração do periódico.

\section{Formação}

Nível de titulação dos membros do corpo editorial. Utilizou-se a seguinte escala: graduação; mestrado; doutorado.

\section{$\underline{\text { Produtividade }}$}

Número de artigos publicados pelos membros do corpo editorial no triênio 2007-2009. Devido à grande quantidade de membros, 1340, esta parte da análise foi realizada com uma amostra aleatória de $10 \%$ do total, isto é, 134 membros, divididos equitativamente entre os periódicos e selecionados aleatoriamente. Esta informação foi levantada mediante consulta aos currículos Lattes desses indivíduos. O corpo foi considerado produtivo se a média de artigos por docente no triênio era superior à média da área à qual o periódico é vinculado. Ressalta-se que 31 (24\%) periódicos não informavam os membros do corpo editorial e 41 (32\%) utilizavam outra nomenclatura para tal corpo, como: conselho editorial, comitê científico, comissão editorial, comitê técnico científico e conselho científico.

Devido à diversidade de nomenclaturas, foi necessário analisar se os membros apresentados representavam o Corpo Editorial ou o Conselho Editorial. Para isso, utilizaram-se os seguintes critérios para identificação do Corpo editorial, de acordo com Trzesniak (2009).

- Apresentar mais que nove membros (normalmente característica do conselho); 
- Apresentar membros diversificados institucionalmente e geograficamente. Além de ser uma característica do corpo, esse não atua em conjunto, ou seja, não precisa se reunir, diversamente do conselho editorial.

\section{Autores}

Verificou-se a afiliação de primeiros autores de artigos publicados no ano de 2009. Apurou-se o número de autores brasileiros e de autores estrangeiros no mesmo ano.

\section{Regras de Submissão de Artigos}

\section{Percentual de trabalhos inéditos}

Calculou-se para cada periódico a proporção de trabalhos inéditos publicados nos números do ano de 2009. Utilizou-se como padrão mínimo $40 \%$ de trabalhos inéditos. $O$ ideal seria que os periódicos informassem o percentual de trabalhos inéditos, mas isso raramente acontece.

Critérios de formatação e normalização

Completeza e clareza na especificação das orientações relativas à formatação e normalização dos trabalhos.

\section{Arbitragem por Pares}

\section{Procedimentos de avaliação}

Completeza e clareza das informações quanto a procedimentos de avaliação dos manuscritos.

\section{Datas do processo de avaliação}

Clareza das informações a respeito de datas do processo de avaliação, com ao menos as datas de submissão e de aprovação dos trabalhos.

\section{Outros aspectos formais}

- Idade do periódico;

- Formato (impresso e eletrônico ou somente eletrônico); 
- Idioma de publicação dos artigos.

\section{Impacto dos periódicos}

Para calcular o impacto de cada periódico utilizou-se o software Publish or Perish. O programa recupera e analisa citações acadêmicas de um determinado autor ou periódico. Utiliza o Google Acadêmico para obter as citações brutas, depois analisa as citações e apresenta uma grande variedade de métricas em um formato amigável aos usuários (HARZING, 2007).

Uma das métricas apresentadas é o índice $\mathrm{H}$. Tal índice foi proposto por Hirsch em 2005 para calcular do impacto de cientistas. O cálculo é feito da seguinte maneira: um cientista tem índice $\mathrm{H}$ se $\mathrm{H}$ dos seus $\mathrm{N}$ artigos possuem pelo menos $\mathrm{H}$ citações cada, e os outros artigos tem menos de $\mathrm{H}$ citações cada. Por exemplo, um pesquisador com índice $\mathrm{H}$ de "7" possui sete artigos com pelo menos sete citações cada.

Braun, Glanzel e Schubert (2006) sugeriram que o índice H poderia ser útil para calcular o impacto de periódicos. Primeiro, pois é insensível a um excesso acidental de artigos não citados e também a um ou vários artigos altamente citados. Segundo, pois combina o efeito de quantidade (número de publicações) e qualidade (índice de citação) de uma maneira bastante específica e equilibrada, que deve reduzir a aparente supervalorização de alguns pequenos periódicos de revisão. $O$ índice $\mathrm{H}$ de periódicos não deve ser calculado para todo o tempo de vida do periódico, mas sim para um período definido (BRAUN; GLANZEL; SCHUBERT, 2006).

Optou-se pela utilização deste programa, pois se utiliza do Google Acadêmico para fazer a análise de citações, mecanismo que, além de ser gratuito, demonstra ser eficiente para o cálculo do impacto de periódicos e pesquisadores. Além disso, grande parte dos periódicos analisados não está indexada nas bases de dados do ISI ou Scopus, portanto, seria mais difícil calcular um índice para representar o impacto dos periódicos. 
Optou-se por apresentar o índice $\mathrm{H}$, pois é um índice relativamente novo que tem sido utilizado na análise de citações, e porque, também, o Fator de Impacto, como observado no referencial teórico possui diversas desvantagens. Apesar do índice $\mathrm{H}$ ainda não estar consolidado, apresenta um método de análise de impacto mais apropriado.

Tabela 1 - Descrição das variáveis analisadas

\begin{tabular}{|c|c|c|}
\hline Variável analisada & Aspectos analisados & Definição \\
\hline \multirow{4}{*}{ Corpo Editorial } & Afiliação & Vínculo institucional \\
\hline & Formação & $\begin{array}{c}\text { Titulação: Graduação, Mestrado } \\
\text { ou Doutorado }\end{array}$ \\
\hline & Nacionalidade & Brasileiro ou estrangeiro \\
\hline & Produtividade & $\begin{array}{l}\text { Número de artigos publicados } \\
\text { (2007-2009) superior (produtivo) } \\
\text { ou inferior (não produtivo) à } \\
\text { mediana da área do periódico }\end{array}$ \\
\hline \multirow[t]{2}{*}{ Autores } & Afiliação & Vínculo institucional \\
\hline & Nacionalidade & Brasileiro ou estrangeiro \\
\hline \multirow{2}{*}{$\begin{array}{c}\text { Regras de submissão dos } \\
\text { artigos }\end{array}$} & $\begin{array}{c}\text { Critérios de formatação e } \\
\text { normalização }\end{array}$ & $\begin{array}{c}\text { Completeza e clareza na } \\
\text { apresentação }\end{array}$ \\
\hline & Percentual de trabalhos inéditos & $\begin{array}{c}\text { Preferencialmente igual ou } \\
\text { superior a } 40 \%\end{array}$ \\
\hline \multirow[t]{2}{*}{ Arbitragem por pares } & Datas do processo de avaliação & $\begin{array}{l}\text { Datas de recebimento e } \\
\text { aceitação dos artigos }\end{array}$ \\
\hline & Procedimentos de avaliação & $\begin{array}{l}\text { Completeza e clareza das } \\
\text { informações }\end{array}$ \\
\hline \multirow{3}{*}{ Outros aspectos formais } & Formato & $\begin{array}{l}\text { Impresso / eletrônico ou } \\
\text { somente eletrônico }\end{array}$ \\
\hline & Idioma & Idioma de publicação dos artigos \\
\hline & Idade & Tempo de vida dos periódicos \\
\hline Impacto dos periódicos & Índice H & Valor que representa o impacto \\
\hline
\end{tabular}




\section{RESULTADOS E DISCUSSÃO}

\subsection{Corpo Editorial}

Os dados sobre o Corpo Editorial foram obtidos a partir de 48 periódicos, pois os outros 30 , isto é, $38 \%$ do total, não informavam a sua composição ou não apresentavam Corpo Editorial algum. Ressalta-se, entretanto, que a apresentação da composição do Corpo Editorial é um critério essencial para a qualidade do periódico. A SciELO (2004), por exemplo, utiliza este critério para admitir periódicos na coleção.

Além disso, Trzesniak (2009) lembra que o Corpo Editorial é uma das garantias de credibilidade científica de periódicos. Tal grupo é responsável por auxiliar o editor a tomar decisões com relação à publicação de originais. Além disso, como sugere Trzesniak (2009, p. 97):

\footnotetext{
Preparar uma revista científica exige uma grande dedicação e implica dar seu tempo para melhorar o trabalho de outros pesquisadores, em detrimento de seus próprios projetos. Somente com o envolvimento de uma equipe isso pode ser feito sem que o editor fique seriamente prejudicado em sua carreira de pesquisador
}

Portanto, pode-se perceber a importância de um Corpo Editorial e de uma equipe bem estruturada para a boa gestão de um periódico científico e, consequentemente, para sua qualidade como instrumento de disseminação de informações. 


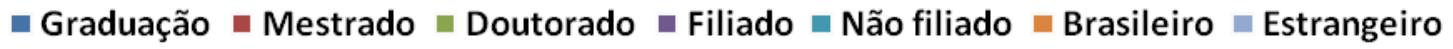

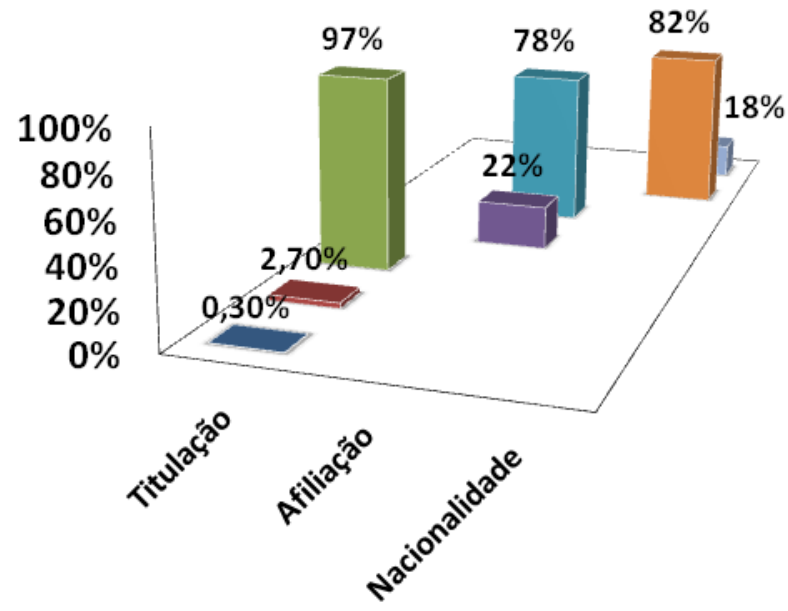

Gráfico 1 - Titulação, Afiliação e Nacionalidade dos membros do Corpo Editorial

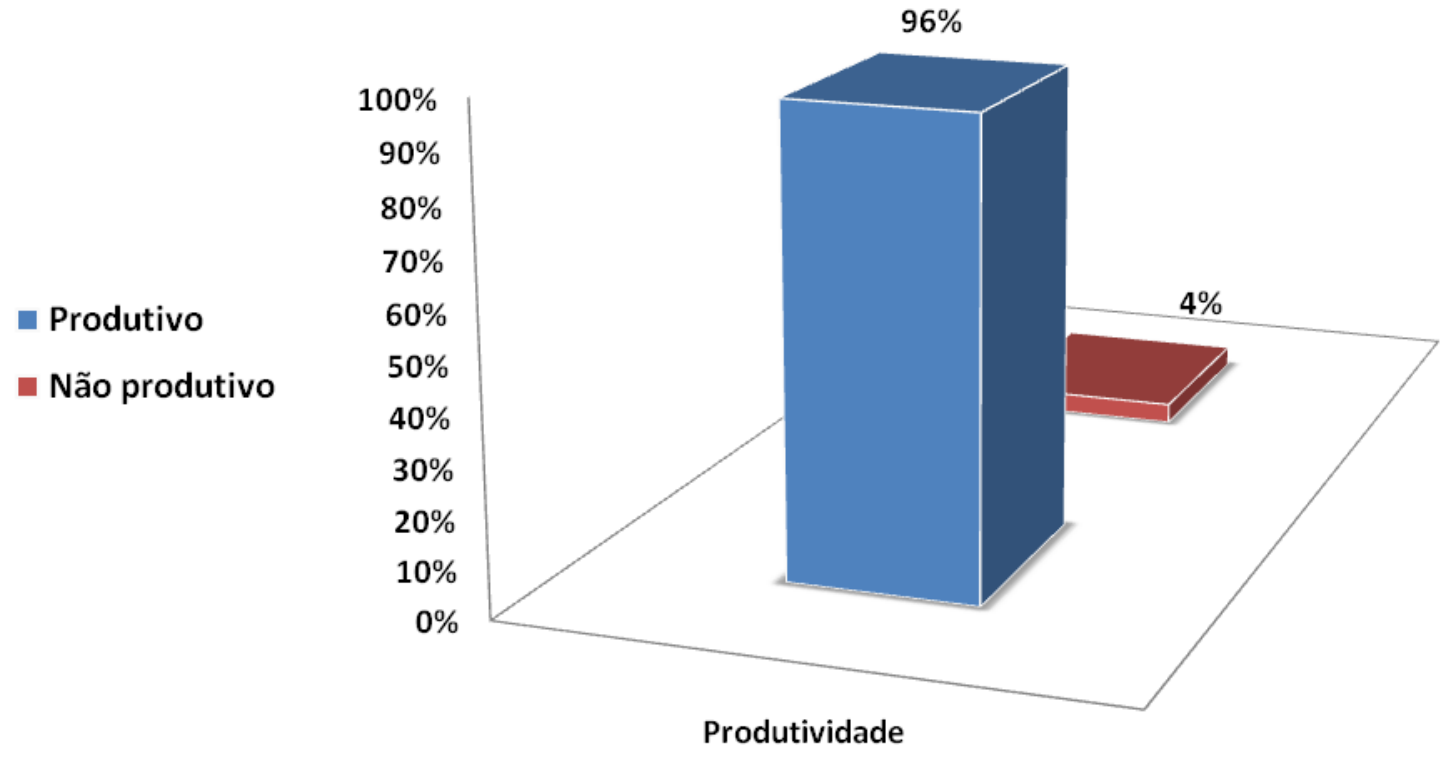

Gráfico 2 - Produtividade do Corpo Editorial

Ao analisar as estatísticas sobre o Corpo Editorial, percebe-se que a maior parte dos membros são filiados a instituições diversas da que edita o periódico. Tal fator é essencial, pois, como afirma Trzesniak (2009, p. 90): 
[...] é um colegiado necessariamente multi-institucional, constituído por pesquisadores especialistas distribuídos uniformemente tanto cientificamente (ou seja, pelas áreas e subáreas das ciências e da tecnologia a que o periódico se dedicar) como geograficamente (isto é, pelas regiões onde a revista pretende circular representativamente) [Grifo do autor]

A diversidade dos membros do Corpo Editorial é um dos critérios de avaliação de periódicos utilizado por pelo menos três instituições: Thomson Scientific (2009), para admissão de periódicos nas bases de dados do ISI Web of Science; SciELO (2004), para admissão de periódicos na coleção; Associação Brasileira de Editores Científicos (ABEC) (2009), para seleção de periódicos científicos eletrônicos para financiamento.

Foram encontrados, ainda, critérios semelhantes nos estudos de: i) Krzyzanowski e Ferreira (1998) ao avaliar periódicos científicos e técnicos brasileiros; ii) Ali, Young e Ali (1996) em que foi elaborada uma lista de verificação de aspectos de qualidade para decisões de financiamento; iii) Trzesniak (2006), como um dos critérios para avaliação de periódicos da área de Educação.

A formação acadêmica de quase todos os membros do Corpo Editorial dos periódicos pesquisados é adequada, pois possuem doutorado. Além disso, a produtividade da maioria dos membros que compuseram a amostra ultrapassa ou iguala a produtividade média da área do conhecimento a qual o periódico pertence. Isso pode significar que os membros dos corpos editoriais pesquisados possuem suficiente envolvimento com atividades científicas e de pesquisa, fator considerado necessário a membros de um colegiado que seria responsável por manter o nível de qualidade do periódico.

Apesar dos resultados serem positivos, é necessário lembrar que $38 \%$ dos periódicos não informam a composição do Corpo Editorial, o que diminui sobremaneira sua qualidade. Se a análise considerasse a totalidade dos periódicos, os resultados mostrariam que o conjunto possui qualidade inferior ao mínimo necessário. 


\subsection{Autores dos artigos publicados}

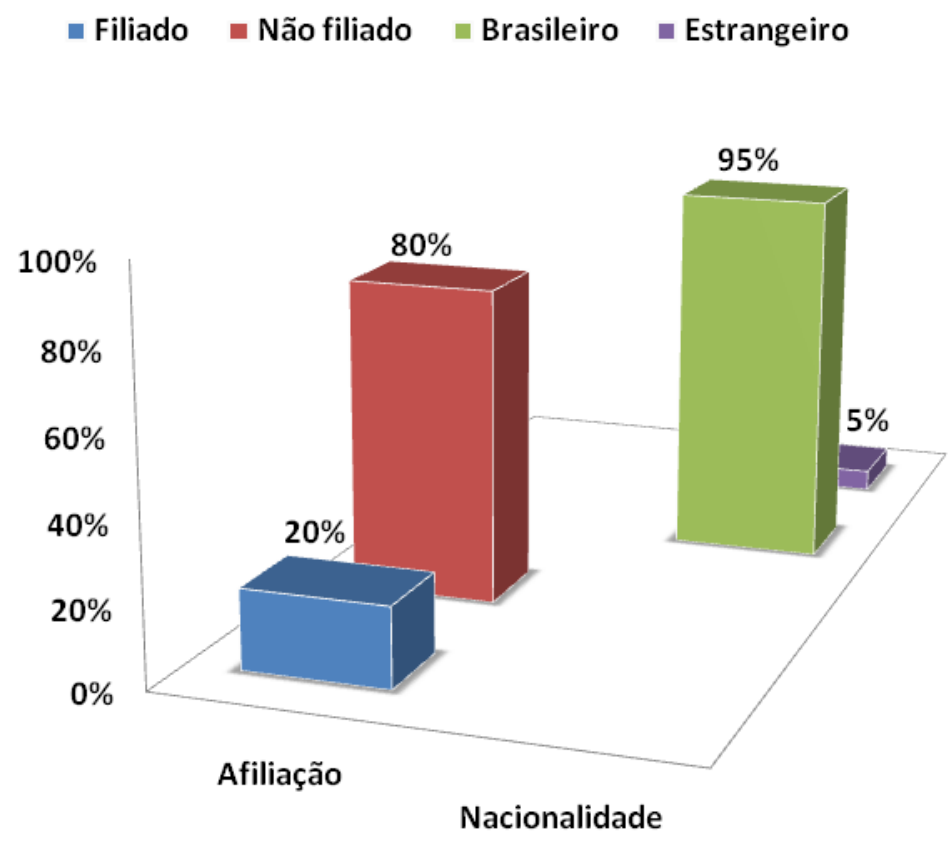

Gráfico 3 - Afiliação e Nacionalidade dos autores

Os resultados do estudo revelam que o percentual de autores externos (não filiados à instituição editora) superou o predomínio absoluto (70\%), que seria o mínimo recomendável por Ferreira (2005) para evitar a endogenia. Concordando com a autora, Trzesniak (2006) recomenda que mais de $60 \%$ dos artigos publicados sejam de autores de instituições diferentes da que edita o periódico, excluídos os autores estrangeiros. No caso dos últimos, é recomendada a publicação de no mínimo $10 \%$ de artigos de autores estrangeiros durante os três últimos anos. A Thomson Scientific (2009) estabelece como critério, de maneira mais geral, a diversidade internacional entre os autores do periódico.

Com relação à nacionalidade dos autores, deve-se ressaltar que a avaliação foi realizada somente com os primeiros autores e do ano de 2009. Portanto, é explicável que não haja $10 \%$ de autores estrangeiros, como especificado por Trzesniak (2006). Entretanto, os periódicos apresentaram 5\% de autores estrangeiros, que pode ser considerada uma boa proporção. 
Diferentemente do estudo realizado anteriormente (GUIMARÃES; COSTA, 2008), optou-se por não avaliar a formação e produtividade dos autores. Apesar de este fator ser considerado importante por Ferreira (2005), sua avaliação é criticável porque pode significar um direcionamento e uma preferência por um determinado segmento de autores. Além disso, se o periódico estabelecer como política editorial a prioridade para autores mais maduros estaria criando uma barreira aos novos entrantes e, consequentemente, à oxigenação e à evolução da ciência. Além do mais, o fato de um autor ser sênior não significa, necessariamente, que o seu artigo terá qualidade superior à de um artigo de autoria de um pesquisador iniciante. Isto é, a senioridade não garante, per se, a qualidade do trabalho.

Calvert e Zengzhi (2001) corroboram essa idéia, ao ressaltarem que, apesar de editores de periódicos ficarem satisfeitos em publicar um artigo de um autor com boa reputação, eles devem se conscientizar de que muitos artigos serão de autores cujos nomes não atraem nenhuma atenção particular. A avaliação de qualidade dos artigos, portanto, deve ser baseada no próprio mérito, o qual se refere a oito fatores, nomeadamente: originalidade e inovação; relevância para trabalhos anteriores; relevância para o corpo de conhecimentos da área; objetividade; escrita clara; qualidade dos argumentos; implicações teóricas e práticas; estar de acordo com os objetivos editoriais do periódico.

\subsection{Dados gerais dos periódicos estudados}

Como explicitado na metodologia, os periódicos que compuseram a amostra deveriam, necessariamente, estar classificados em suas devidas áreas do conhecimento. Portanto, como se pode perceber pelo gráfico 4 , algumas áreas possuem mais periódicos que outras. 


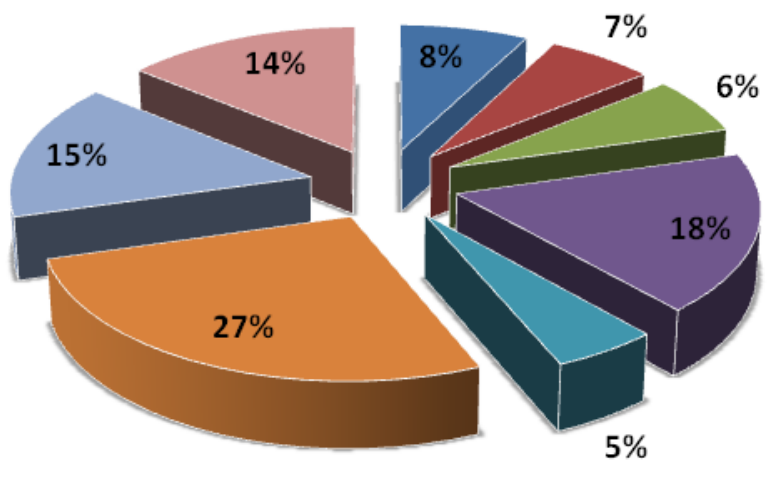

\author{
- Ciências agronômicas e \\ veterinárias \\ - Ciências biológicas \\ - Ciências matemáticas e \\ naturais \\ - Ciências médicas e da saúde \\ E Engenharias e computação \\ - Ciências sociais aplicadas \\ - Ciências humanas \\ - Linguagens e artes
}

Gráfico 4 - Divisão dos periódicos da amostra por área do conhecimento

Tal diferença também pode ser explicada por outros aspectos, como o padrão de publicação das áreas do conhecimento. Mueller (2005) realizou um estudo para verificar os canais preferenciais de publicação de cada área do conhecimento. Para isso, coletou dados das tabelas da CAPES de 1995 a 2002, verificando as publicações em periódicos (nacionais e estrangeiros), anais (nacionais e estrangeiros), livros e capítulos de livros e concluiu que:

- Pesquisadores das áreas de Ciências Exatas e Naturais e Ciências Biológicas preferem publicar em periódicos estrangeiros e muito pouco em outros canais;

- Pesquisadores de Ciências da Saúde preferem publicar em periódicos nacionais, mas também publicam em estrangeiros, e pouco utilizam outros canais;

- Pesquisadores das Engenharias dão preferência à publicação em anais de eventos, bem acima do número de publicações em periódicos;

- Pesquisadores de Ciências Sociais Aplicadas preferem publicar em periódicos nacionais e livros. Mas também publicam, em menor escala, em periódicos estrangeiros, eventos nacionais e capítulos de livros; 
- Pesquisadores de Ciências Humanas e de Linguística, Letras e Artes preferem publicar em periódicos nacionais e em capítulos de livros.

Percebe-se, portanto, que as áreas de Ciências Matemáticas e Naturais e Ciências Biológicas provavelmente possuem menos periódicos no SEER, pois não valorizam a publicação em periódicos nacionais, mas sim em estrangeiros. Consequentemente, a criação e a edição de periódicos brasileiros acontecem em menor escala. O mesmo se passa com a área de Engenharias e Computação, que priorizam a publicação em anais de eventos.

A variável 'idade dos periódicos' não foi estudada como critério de qualidade em si. Perceber e analisar a distribuição de idade dos periódicos envolveria uma análise de sustentabilidade que, apesar de ser um aspecto importante de ser estudado, não é objeto do presente estudo. Observando-se o gráfico 5 , verifica-se que existem mais periódicos com idade entre quatro e 20 anos e menos entre 21 e 50. No entanto, não é possível afirmar que poucos periódicos sobrevivem mais que vinte anos. Tal afirmação pode ser uma hipótese a ser estudada em outra oportunidade.

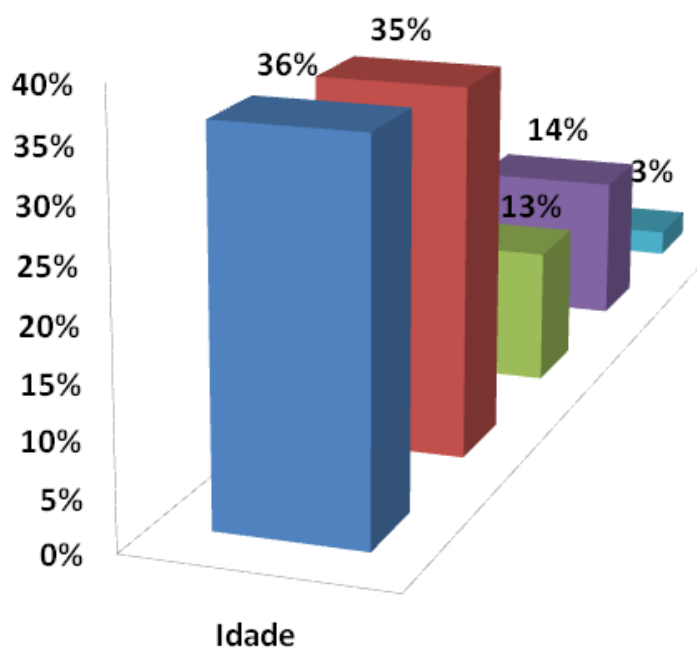

Gráfico 5 - Idade dos periódicos 
A variável idade foi utilizada para avaliar se os periódicos mais antigos, ou seja, mais consolidados, possuem índice $\mathrm{H}$ maior ou não. Isto é, se o impacto do periódico aumenta com sua idade. Para isso, foi necessário calcular o Coeficiente de Correlação de Pearson. Tal coeficiente varia de 1 a -1 , sendo 1 uma correlação positiva perfeita (se uma variável aumenta a outra também aumenta), e -1 uma correlação negativa perfeita (se uma variável diminui a outra também diminui). Se o valor do coeficiente for zero, significa que não existe correlação entre as variáveis, ou seja, os valores de uma variável aumentam ou diminuem independentemente dos valores da outra variável em questão.

O cálculo do coeficiente apresentou como resultado 0,39. A correlação do índice $\mathrm{H}$ dos periódicos com sua idade pode ser representada pelo gráfico de dispersão apresentado a seguir.

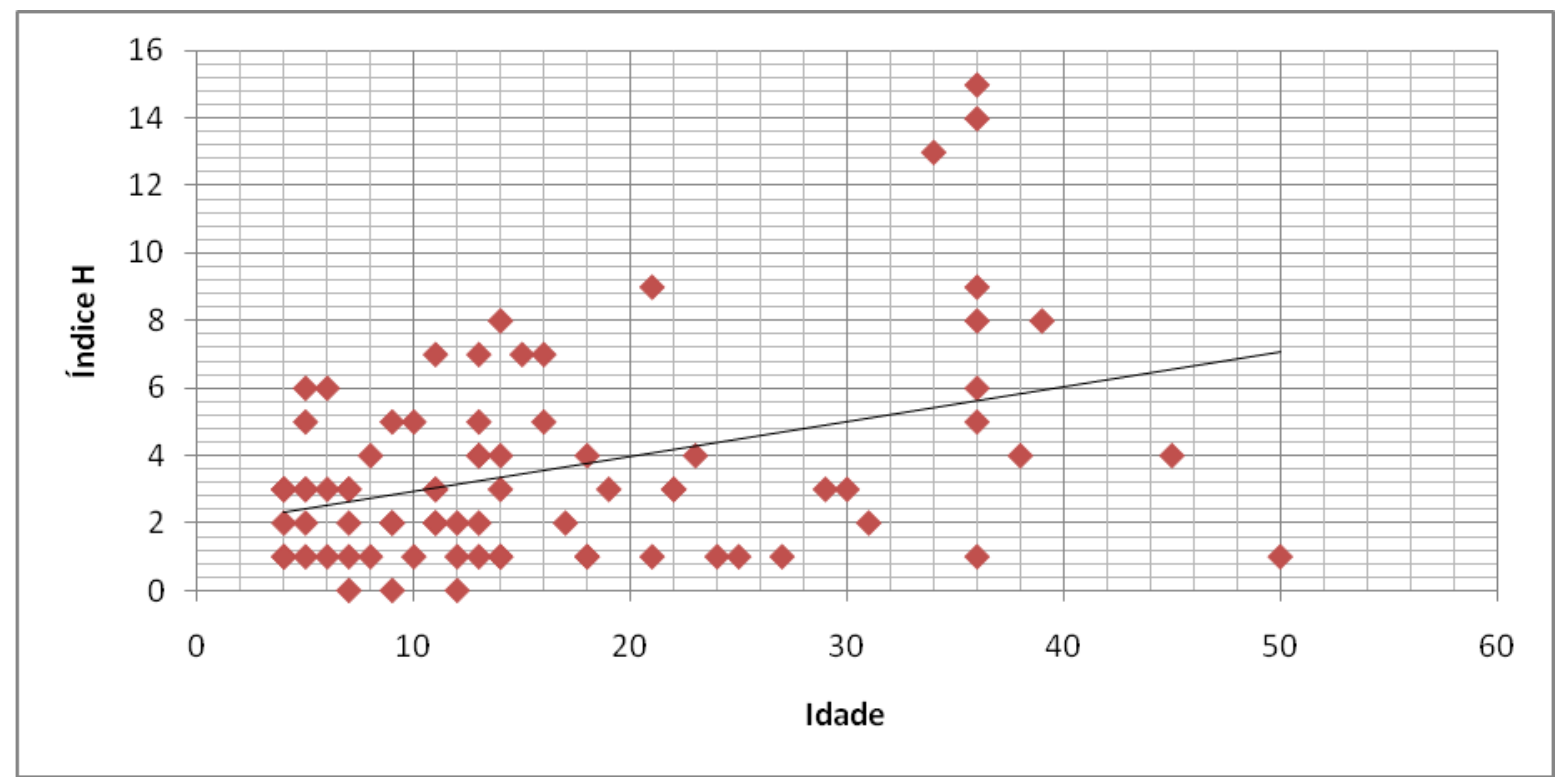

Gráfico 6 - Correlação do índice H com a idade dos periódicos

Pode-se dizer que existe uma correlação positiva moderada, revelando tendência de aumento do índice $\mathrm{H}$ com o aumento da idade dos periódicos. No entanto, no caso da amostra, existem exceções que não acompanham a mesma tendência e possuem índice $\mathrm{H}$ menor com idade avançada. Portanto, não é possível afirmar com certeza que periódicos mais antigos possuem maior impacto. Além do mais, isto depende de outros fatores não estudados nesta pesquisa. 
O gráfico 7 apresenta o idioma de publicação dos artigos. Esta informação foi coletada nos sites dos periódicos, em geral na área de instruções aos autores, onde são informados os idiomas que o periódico aceita para publicação do artigo.

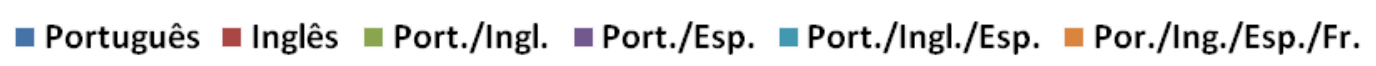
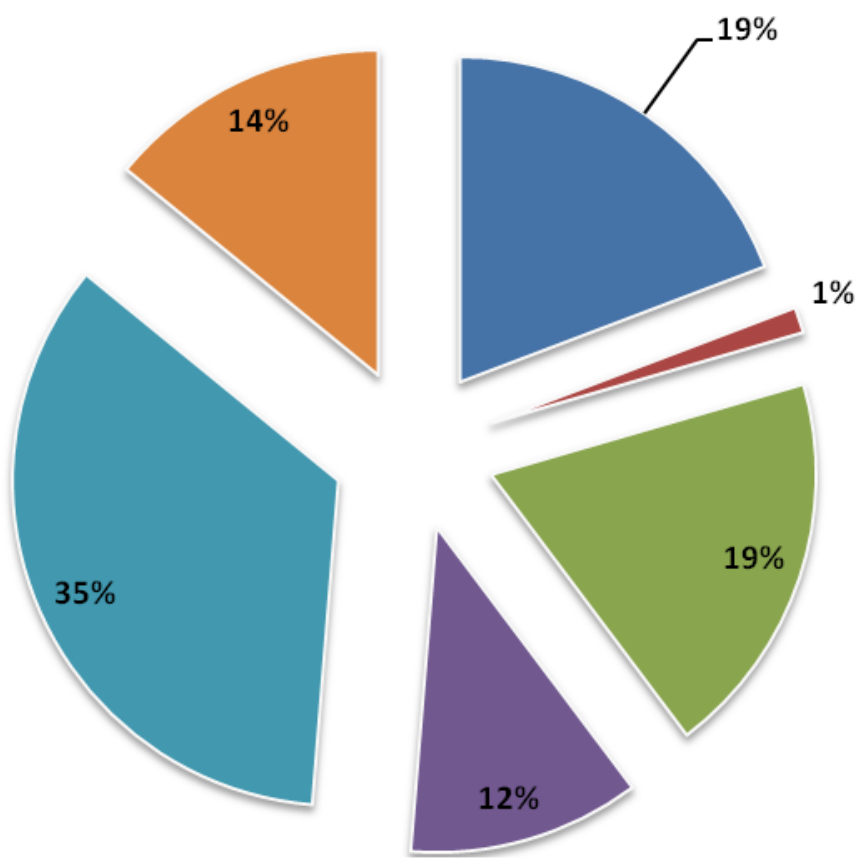

Gráfico 7 - Idioma de publicação dos artigos

Procurou-se avaliar a correlação do idioma de publicação dos artigos com o índice $\mathrm{H}$ dos periódicos. Supõe-se que os periódicos que publicam em idiomas que são mais falados no mundo têm maior alcance e visibilidade, e potencialmente maior impacto, já que seus artigos podem ser lidos por mais pessoas.

Para calcular a correlação, foi feita uma classificação, dentre as principais línguas utilizadas nos periódicos estudados, da menos falada para a mais falada, de acordo com o número de falantes nativos, informação obtida do livro Ethnologue: languages of the world (2009). Portanto, a classificação ficou deste modo: 1) Português 2) Inglês 3) Português e Inglês 4) Português e Espanhol 5) Português, Inglês e Espanhol 6) Português, Inglês, Espanhol e Francês.

O índice de correlação de Pearson obtido foi de -0,038. Isto significa que praticamente não existe correlação entre as variáveis, ou seja, os valores são quase 
independentes. Entretanto, afirmações conclusivas não podem ser retiradas da análise. A informação sobre o idioma dos artigos fornecida pelos periódicos não significa necessariamente que os periódicos publicam regularmente artigos nos idiomas especificados.

O gráfico 8 mostra o percentual de periódicos impressos e eletrônicos e somente eletrônicos. Ressalta-se que 5 dos 12 periódicos em meio eletrônico migraram, ou seja, eram impressos anteriormente e optaram por manter somente a versão eletrônica. Os periódicos somente eletrônicos pertencem às seguintes áreas do conhecimento: Ciências Biológicas (2); Ciências Matemáticas e Naturais (2); Ciências Médicas e da Saúde (2); Engenharias e Computação (1); Ciências Sociais Aplicáveis (3); Linguagens e Artes (2). Ressalta-se ainda que dois dos periódicos somente eletrônicos (e que não migraram do meio impresso) possuem índice $\mathrm{H}$ de 5 e ficam entre os $27 \%$ periódicos com maior índice $\mathrm{H}$. Tais periódicos pertencem às áreas de Ciências Biológicas e Ciências Médicas e da Saúde.

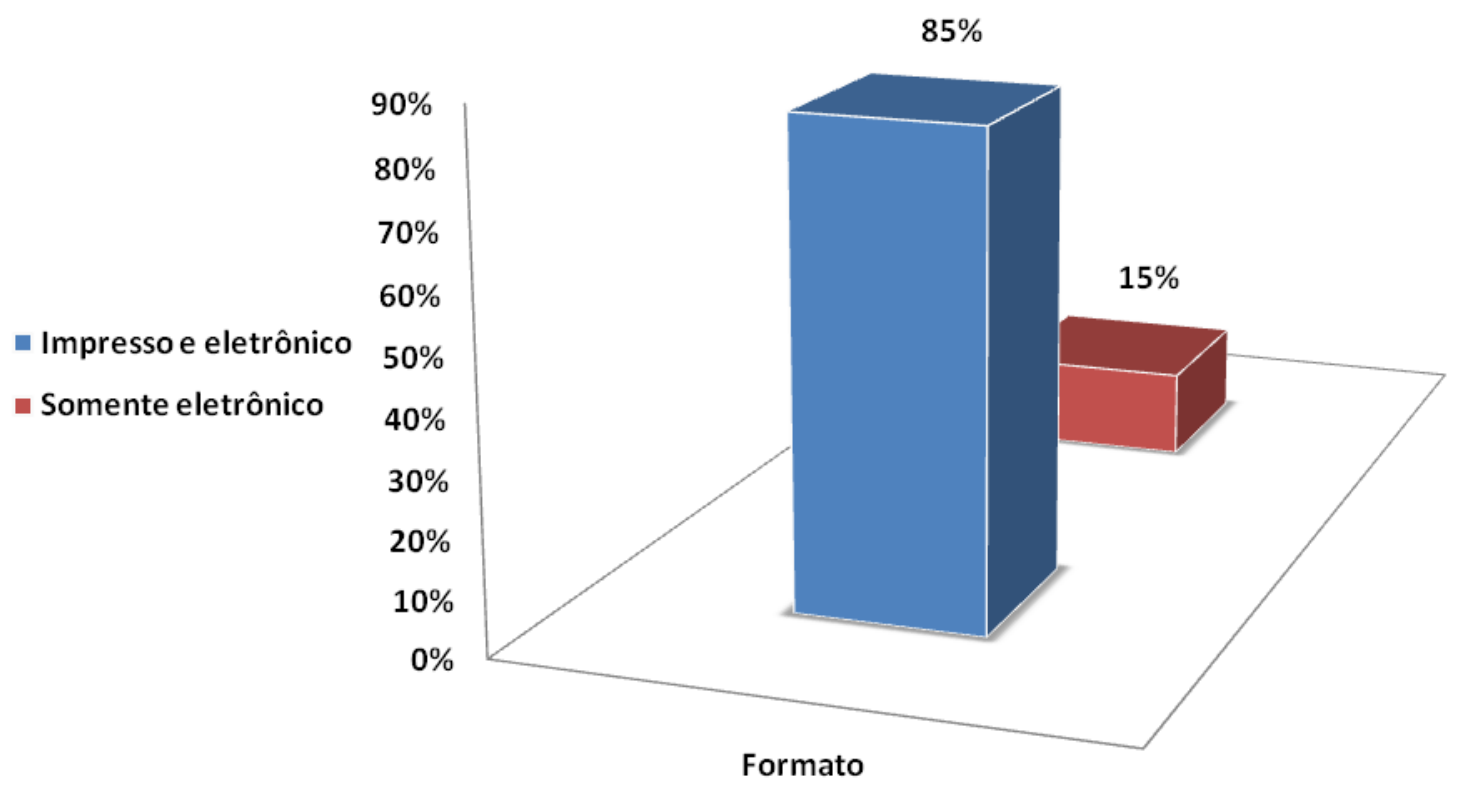

Gráfico 8 - Formato dos periódicos

Com relação aos critérios de formatação e normalização, o gráfico 9 mostra o percentual de periódicos que explicitam tais regras numa classificação que varia de "ruim" a "bom", em termos de clareza e completeza na instrução aos autores com relação às regras do periódico quanto à formatação e normalização. 


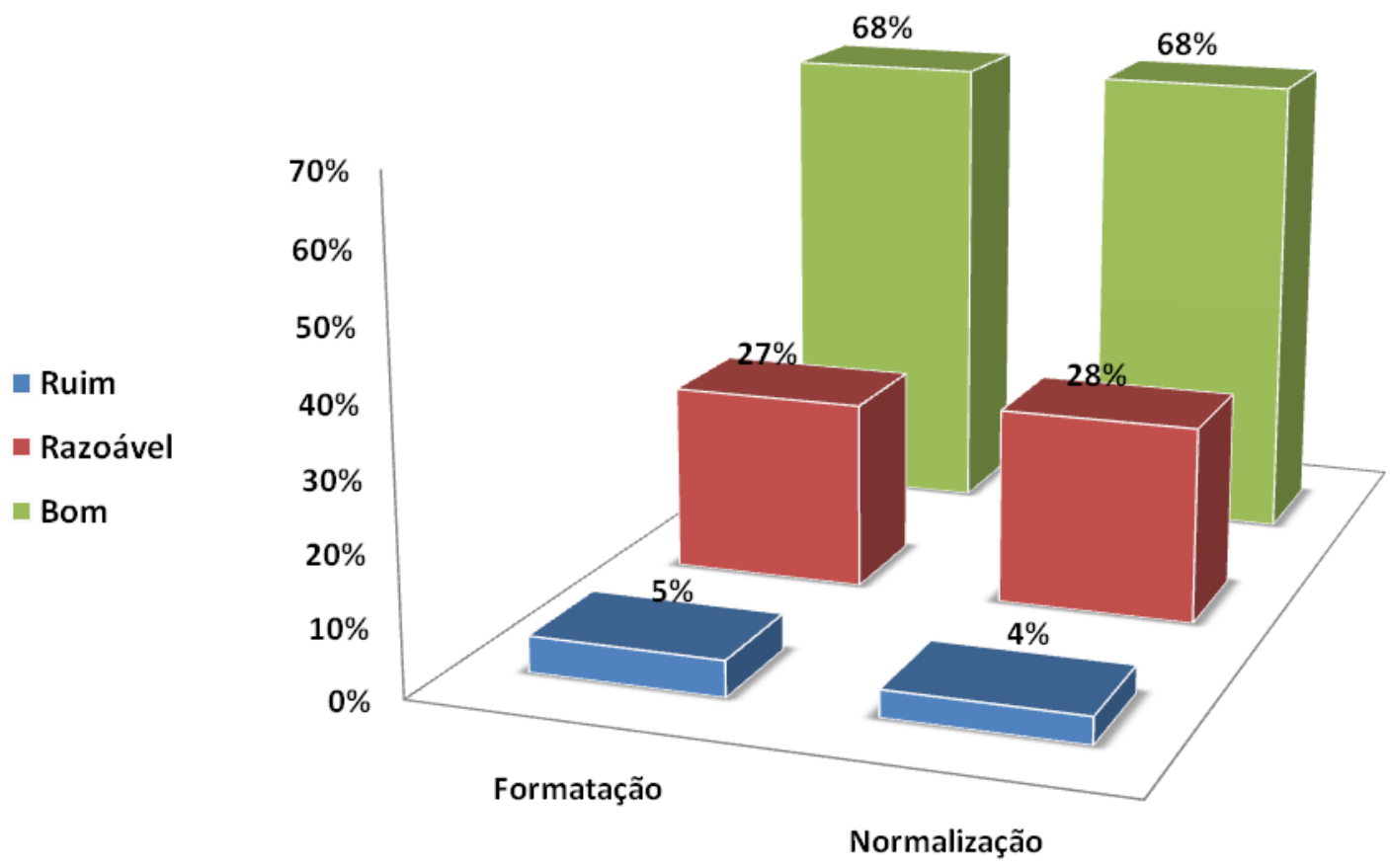

Gráfico 9 - Apresentação das regras de Formatação e Normalização

Observa-se que $68 \%$ dos periódicos obtiveram a melhor classificação em termos de formatação e normalização. Isto significa que tais periódicos apresentam instruções de forma clara e abrangente, o que permite melhor compreensão por parte dos autores e evita o surgimento de dúvidas e, consequentemente, erros na elaboração dos artigos. Desta forma, o processo editorial anda mais rapidamente, já que provavelmente poucos artigos voltam aos autores por erros de formatação e normalização (identificados na primeira fase do processo, na avaliação preliminar pelos editores).

Exemplos de boa apresentação de regras de formatação e normalização: indicação das normas a serem utilizadas para formatação e normalização (ABNT, APA, Vancouver, etc.); indicação da estrutura do artigo (nomes padronizados para os títulos das seções); número máximo de páginas; formato do arquivo a ser enviado e forma de envio; indicações sobre o posicionamento de figuras e tabelas; idiomas aceitos para publicação; exemplos de referências e citações; outras informações específicas do periódico. Alguns periódicos forneciam um modelo de documento com instruções para preenchimento. 
Os periódicos com classificação "razoável" não apresentam tudo o que é necessário para deixar o autor sem nenhuma dúvida. Ou seja, apresentam as regras, mas falham na completeza (prover todas as informações necessárias ao completo entendimento) e na clareza (fornecer informações de forma didática e compreensível) de sua apresentação, dificultando o entendimento por parte dos autores. Os periódicos que obtiveram classificação "ruim" não apresentavam as regras de formatação e normalização.

No que se refere à avaliação dos artigos, percebe-se pelo gráfico 10 que uma minoria dos periódicos (17\%) cumpre este requisito de forma completa. Tais periódicos explicitam como acontece o processo de avaliação dos trabalhos e, além disso, apresentam os critérios utilizados na avaliação. Os classificados como "razoável" somente apresentam o processo de avaliação, ou seja, por quais atores do processo editorial o trabalho passará, quantos pareceristas avaliam o trabalho, o que acontece se as avaliações forem contraditórias e quais os procedimentos a serem seguidos pelo autor após o recebimento dos pareceres. Os periódicos classificados como "ruim" não especificam nem o processo e nem os critérios de avaliação, ou não apresentam explicação clara e suficiente sobre o processo de avaliação dos trabalhos.

- Ruim

- Razoável

Boa

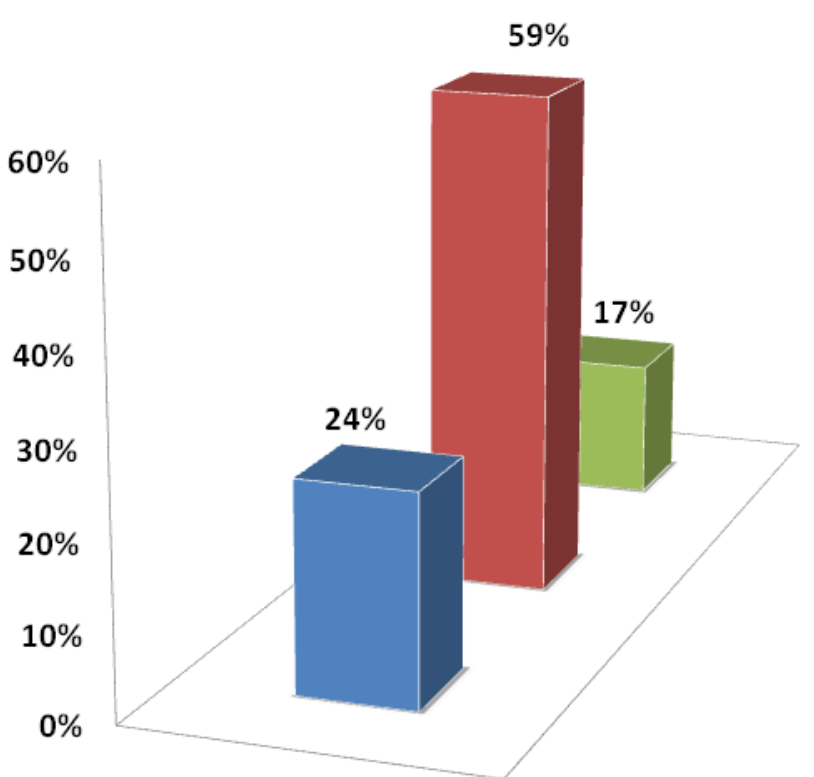

Avaliação 


\section{Gráfico 10 - Apresentação dos critérios de avaliação}

No estudo realizado por Stumpf (2008) com periódicos da área de comunicação, averiguou-se que normalmente os pareceristas não recebem uma lista com itens a serem observados nos artigos. Em geral, os editores solicitam uma avaliação descritiva, em forma de redação, apontando os pontos fortes e fracos do trabalho, além de sugestões de melhoria.

A avaliação descritiva é importante, pois permite uma explicação mais elaborada com relação aos aspectos avaliados no artigo. Entretanto, também deveria haver uma avaliação por meio de lista de verificação, com itens específicos a serem observados nos artigos. Tal procedimento permite maior padronização do processo de avaliação, e também facilita a elaboração dos pareceres, já que os pareceristas passam a conhecer os aspectos considerados essenciais para aceitação de artigos no periódico em questão.

Além disso, a especificação dos critérios observados para a avaliação e aprovação dos artigos, permite que os autores tomem conhecimento dos pontos mais importantes para que seu artigo seja aceito para publicação. Podem, assim, evitar certas idas e vindas do artigo entre o periódico e o autor, agilizando o processo de avaliação.

O gráfico 11 mostra que $73 \%$ dos periódicos apresentam as datas do processo de arbitragem, especificamente, de recebimento e aceitação de cada artigo.

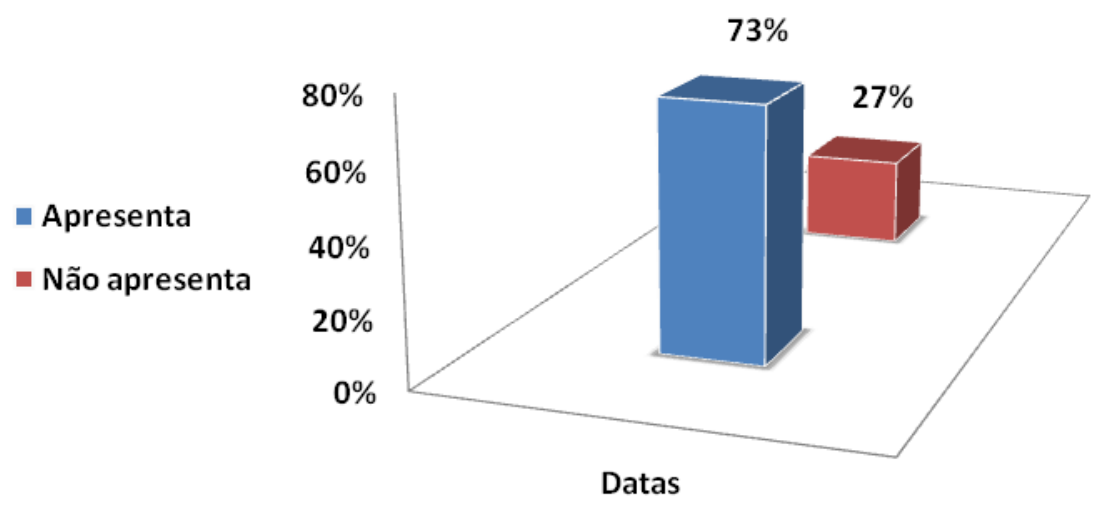

Gráfico 11 - Apresentação das datas do processo de arbitragem 
Além de ser um critério considerado importante na avaliação por parte de agências de fomento e mecanismos indexadores, a apresentação das datas demonstra preocupação dos editores com relação à agilidade do processo de avaliação e publicação dos artigos.

O gráfico 12 classifica os periódicos de acordo com o percentual de trabalhos inéditos que publicaram no ano de 2009.

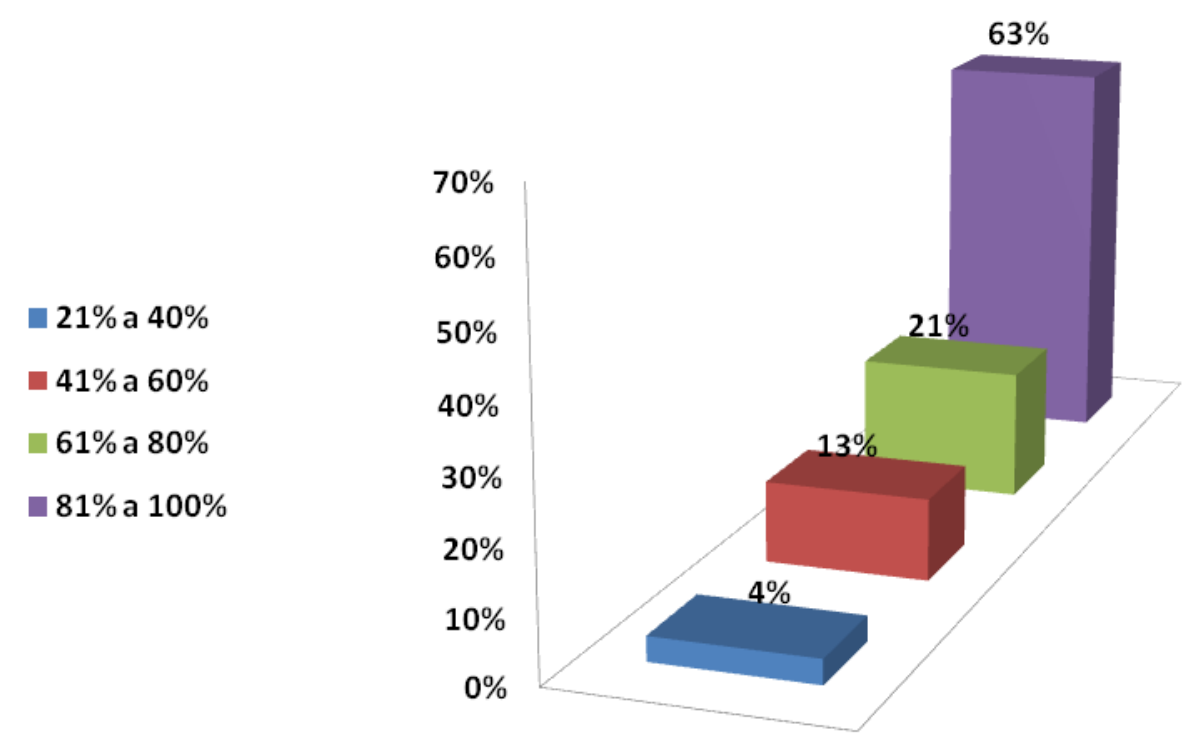

Gráfico 12 - Percentual de trabalhos inéditos dos periódicos

Percebe-se que somente $4 \%$ dos periódicos publicaram menos de $40 \%$ de trabalhos inéditos, o mínimo considerado por Ferreira (2005) para periódicos científicos de qualidade. Mas a grande maioria dos periódicos (96\%) publicou, em 2009, mais que o mínimo de manuscritos inéditos. Isto significa que tais periódicos primam pela publicação de artigos inovadores em suas áreas do conhecimento.

O gráfico 13 mostra que $73 \%$ dos periódicos possuem índice $\mathrm{H}$ de 0 a 4 e $27 \%$ possuem índice $\mathrm{H}$ de 5 a 15, considerando os anos de 2007 a 2009. Tais resultados podem significar que a maioria dos periódicos não possui um impacto significativo sobre a comunidade científica de suas áreas. Entretanto, o baixo índice $\mathrm{H}$ pode ser explicado por outros fatores, como visibilidade do periódico, idade, indexações etc. 


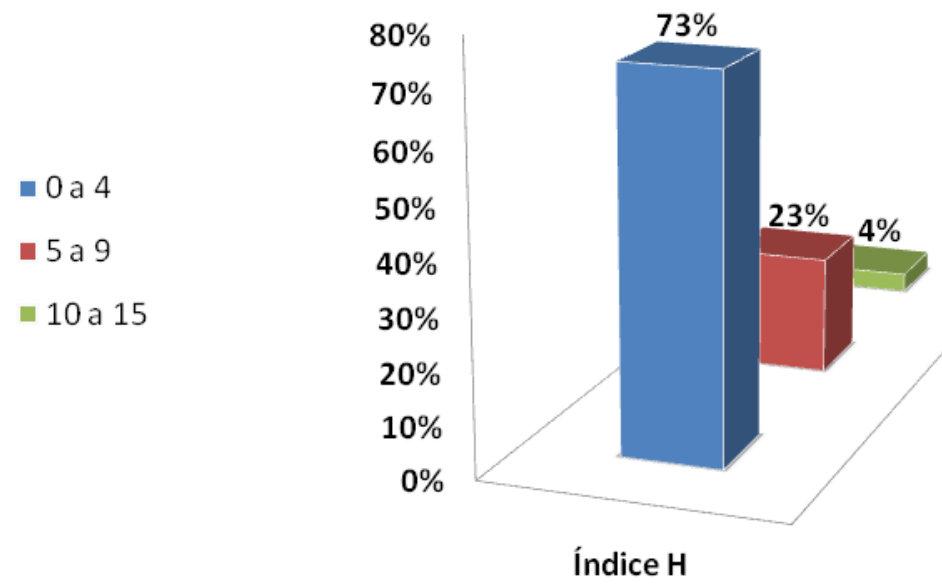

Gráfico 13 - Índice H dos periódicos estudados

Além dos dados brutos sobre o índice $\mathrm{H}$, foi feita uma comparação entre a média do índice $\mathrm{H}$, considerando dois grupos. O primeiro formado pelas áreas: Ciências Agronômicas e Veterinárias, Ciências Biológicas, Ciências Matemáticas e Naturais, Ciências Médicas e da Saúde e Engenharias e Computação, totalizando 34 periódicos. O segundo grupo é formado pelas áreas: Ciências Humanas, Ciências Sociais Aplicadas e Linguagens e Artes, totalizando 44 periódicos.

Para comparar a média do índice $\mathrm{H}$ dos dois grupos, utilizou-se o teste $\mathrm{t}$, pois as duas amostras possuem observações suficientes. A hipótese nula e alternativa são respectivamente as seguintes:

$\mathrm{H}_{0} \rightarrow$ Média do Grupo 1 = Média do Grupo 2. A diferença das médias observadas para os dois grupos podem ser justificadas por fatores casuais.

$\mathrm{H}_{1} \rightarrow$ Média do Grupo $1 \neq$ Média do Grupo 2. A diferença das médias dos dois grupos são reais.

A estatística do teste e os dados necessários para aceitar ou rejeitar a hipótese nula $\left(\mathrm{H}_{0}\right)$ foram calculados com auxílio do programa Excel. A tabela com os resultados consta a seguir. 
Tabela 2 - Teste t de comparação entre duas médias

\begin{tabular}{lll}
\hline & Grupo 1 & Grupo 2 \\
\hline Média & 5 & 2,522727273 \\
\hline Variância & 13,81818182 & 3,41807611 \\
\hline Observações & 34 & 44 \\
\hline Hipótese da diferença de média & 0 & \\
\hline gl & 46 & \\
\hline Stat $t$ & 3,560458958 & \\
\hline $\mathrm{P}(\mathrm{T}<=\mathrm{t})$ uni-caudal & 0,000436784 & \\
\hline $\mathrm{t}$ critico uni-caudal & 1,678660414 & \\
\hline $\mathrm{P}(\mathrm{T}<=\mathrm{t})$ bi-caudal & 0,000873568 & \\
\hline $\mathrm{t}$ crítico bi-caudal & 2,012895567 & \\
\hline
\end{tabular}

Para aceitar ou rejeitar $\mathrm{H}_{0}$ é necessário comparar a probabilidade de significância do teste com o nível de significância adotado. A probabilidade de significância $(P)$ pode ser definida como a probabilidade de tomar uma decisão equivocada caso se rejeite a hipótese nula. Por exemplo, se ao realizar um teste obtém-se um $P$ de 0,003 , existe um risco de $0,3 \%$ de tomar a decisão errada ao rejeitar $\mathrm{H}_{0}$ (BARBETTA, 1999).

$O$ teste realizado retornou uma probabilidade de significância $P$ de 0,000873568 que é menor que o nível de significância de 0,05 . Portanto, o teste rejeita $\mathrm{H}_{0}$ em favor de $\mathrm{H}_{1}$. Isto significa que existem diferenças reais entre o Grupo 1 e o Grupo 2 em termos de média do índice $\mathrm{H}$.

Esse teste demonstra que periódicos das áreas de ciências naturais, matemática e saúde possuem maior impacto, se comparados com periódicos das áreas de ciências sociais, humanas e letras. Tal fato pode ser explicado por distintos fatores.

Um destes fatores é que no Grupo 1 é normal a existência de maior número de artigos com autoria compartilhada, sendo comum a existência de textos com mais de seis autores. Já no Grupo 2, isto não é tão comum, sendo mais normal encontrar artigos produzidos por somente um autor. Observa-se, também, que os artigos do Grupo 1 contêm poucas páginas, enquanto que os do Grupo 2 são em geral mais longos (MUELLER, 2005). 
O fato dos artigos do Grupo 1 possuírem menos páginas e serem escritos por mais de um autor, propicia uma maior produção de artigos. Consequentemente, adotando tal padrão, existem mais chances de vários artigos possuírem alto índice de citações e, portanto, maior impacto na comunidade científica. 


\section{CONCLUSÃO}

O objetivo principal do estudo foi avaliar a qualidade de periódicos científicos brasileiros que utilizam o SEER. A pesquisa obteve como resultados dados relevantes que devem ser levados em consideração para que estes periódicos possam ter qualidade e serem considerados, de fato, científicos. Isso porque, somente assim, passam a ter maior visibilidade e aceitação no meio acadêmico, o que, por sua vez, implica em maior impacto.

Os resultados obtidos permitiram identificar aspectos positivos e negativos com relação aos periódicos estudados.

\section{Aspectos positivos}

- Os periódicos da amostra cumpriram adequadamente os critérios considerados para os Autores;

- O Corpo Editorial de $62 \%$ dos periódicos é produtivo, com boa formação e com poucos membros filiados à instituição editora;

- A maioria dos periódicos apresenta instruções claras e completas relacionadas à formatação e normalização dos artigos;

- A maioria informa nos artigos as datas do processo editorial, principalmente as de recebimento e aceitação;

- A maior parte dos periódicos publica mais que $40 \%$ de artigos inéditos;

\section{Aspectos Negativos:}

- Somente $17 \%$ dos periódicos informam como acontece o processo de avaliação e os critérios utilizados na avaliação dos artigos;

- $38 \%$ dos periódicos não informam a composição do Corpo Editorial;

- Boa parte dos periódicos possui índice H baixo; 


\section{Outros aspectos identificados:}

- Existe uma relação positiva moderada $(0,39)$ entre o aumento do índice $\mathrm{H}$ dos periódicos e sua idade;

- Não existe correlação entre o índice H e o idioma de publicação dos artigos;

- Existe uma diferença significativa entre a média do índice $\mathrm{H}$ das áreas de ciências naturais, matemáticas e da saúde e das áreas de ciências sociais, humanas e linguagens.

Os resultados permitem afirmar que os periódicos estudados atenderam de forma adequada aos critérios estabelecidos para o estudo. $\mathrm{O}$ índice $\mathrm{H}$ baixo da maioria dos periódicos não pode ser considerado um fator negativo. Isto porque mais de $70 \%$ dos periódicos existem há menos de 21 anos, e o índice H está relacionado, mesmo que moderadamente, com a idade dos periódicos.

É importante, no entanto, ressaltar a possibilidade de que os critérios definidos para a intencionalidade da amostra tenham influenciado a seleção de periódicos com qualidade.

Vale ressaltar, também, que a pesquisa avaliou somente uma amostra relativamente pequena, considerando o número total de periódicos existentes no sistema. Seria interessante realizar um estudo com uma amostra mais representativa do sistema como um todo. Entretanto, o estudo trouxe resultados que servem de reflexão aos estudiosos da área e também traz aspectos que ainda podem ser mais aprofundados em estudos posteriores. 


\section{REFERÊNCIAS}

ALBERTS, Bruce. Engaging in a worldwide transformation: our responsibility as scientists for the provision of global public goods. In: ANNUAL MEETING OF THE NATIONAL ACADEMY OF SCIENCES, 139., 2002, Washington, D.C. Anais... Washington, D.C.: [S.I.], 2002. Disponível em:

$<$ http://www.nasonline.org/site/DocServer/speech2002.pdf?doclD=121>. Acesso em: 24 nov. 2007.

ALI, S. Nazim; YOUNG, Harold C.; ALI, Nasser M. Determining the quality of publications and research for tenure or promotion decisions: a preliminary checklist to assit. Library Review, v. 45, n. 1, 1996. Disponível em:

$<$ http://www.emeraldinsight.com/10.1108/00242539610107749>. Acesso em: 05 jan. 2009.

ANTELMAN, Kristin. Do open access articles have a greater research impact? College \& Research Libraries, v. 65, n. 5, p. 372-382, sept. 2004. Disponível em: $<$ http://www.ala.org/ala/acrl/acrlpubs/crljournal/crl2004/crlseptember/antelman.pdf $>$. Acesso em: 14 set. 2007.

ASSOCIAÇÃO BRASILEIRA DE EDITORES CIENTÍFICOS (ABEC). Critérios para seleção de revistas científicas eletrônicas (CNPq/Finep). Disponível em: $<$ http://www.liber.ufpe.br/abec/>. Acesso em: 15 fev. 2009.

BARBETTA, Pedro Alberto. Estatística aplicada às Ciências Sociais. 3. ed. Florianópolis: UFSC, 1999.

BRANIN, Joseph J.; CASE, Mary. Reforming scholarly publishing in the sciences: a librarian perspective. Notices of the AMS, v. 45, n. 4, p. 475-486, Apr. 1998.

Disponível em: <http://www.ams.org/notices/199804/branin.pdf>. Acesso em: 10 nov. 2007.

BRAUN, Tibor; GLANZEL, Wolfgang; SCHUBERT, András. A Hirsch-type index for journals. Scientometrics, v. 69, n. 1, p. 169-173, 2006.

BUDAPEST Open Access Initiative. 2002. Disponível em:

$<$ http://www.soros.org/openaccess/>. Acesso em: 02 out. 2007.

CALVERT, Philip J.; ZENGZHI, Shi. Quality versus quantity: contradictions in LIS journal publishing in China. Library Management, v. 22, n. 4/5, p. 205-211, 2001. Disponível em: <http://www.emeraldinsight.com/10.1108/01435120110388779>. Acesso em: 15 jan. 2009.

COSTA, Sely M. S. O novo papel das tecnologias digitais na comunicação científica. In: MARCONDES, Carlos et al. (Org.). Bibliotecas digitais: saberes e práticas. 2. ed. Salvador, BA: EDUFBA; Brasília: IBICT, 2006. p. 165-183. 
. The impact of computer usage on scholarly communication amongst academic social scientists. 1999. 291f. Tese (Doutorado em Ciência da Informação)Departament of information Science, Loughbourough University, Loughbourough, 1999.

FERREIRA, Aline Alessio et al. Avaliação de periódicos científicos on-line na área do direito. CRB-8 Digital, v. 2, n. 2, p. 12-26, set. 2009. Disponível em: $<$ http://revista.crb8.org.br/index.php/crb8digital/article/viewFile/3/3>. Acesso em: 15 dez. 2009.

FERREIRA, Maria Cecília Gonzaga; KRZYZANOWSKI, Rosaly Favero. Periódicos científicos: critérios de qualidade. Pesquisa Odontológica Brasileira, São Paulo, v. 17, maio 2003. Disponível em: $<$ http://www.scielo.br/scielo.php?script=sci arttext\&pid=S151774912003000500007\&lng=en\&nrm=iso >. Acesso em: mar. 2010.

FERREIRA, Sueli Mara Soares Pinto. Critérios de qualidade para as revistas científicas em comunicação. In: FERREIRA, Sueli Mara Soares Pinto; TARGINO, Maria das Graças (Orgs.). Preparação de revistas científicas: teoria e prática. São Paulo: Reichmann \& Autores, 2005. Disponível em:

$<$ http://revcom2.portcom.intercom.org.br/index.php/estatisticas/article/viewFile/1676/ 1507>. Acesso em: 25 set. 2007.

FONSECA, Ramon Martins Sodoma da et al. Electronic System for Journal Publishing (SEER). In: ICCC INTERNATIONAL CONFERENCE ON ELECTRONIC PUBLISHING, 8., 2004, Brasília. Proceedings... Brasília: CID/UnB, 2004. p. 226-236. Disponível em: <http://elpub.scix.net/data/works/att/226elpub2004.content.pdf>. Acesso em: 05 jan. 2008.

GARVEY, William D.; GRIFFITH, Belver G. Communication and information processing within scientific disciplines: empirical findings. In: GARVEY, William D. Communication: the essence of science. Oxford: Pergamon, 1979.

GINSPARG, Paul. Winners and losers in the global research village. In: JOINT ICSUUNESCO INTERNATIONAL CONFERENCE ON ELECTRONIC PUBLISHING IN SCIENCE, 1996. Paris. Proceedings... Paris: Unesco, 1996. Disponível em: $<$ http://people.ccmr.cornell.edu/ ginsparg/blurb/pg96unesco.html >. Acesso em: 02 dez. 2007.

GUIMARÃES, Luisa Veras de Sandes; COSTA, Sely Maria de Souza. Análise e descrição do estado da arte dos periódicos científicos eletrônicos brasileiros criados por meio do SEER. In: CONGRESSO DE INICIAÇÃO CIENTÍFICA DA UNIVERSIDADE DE BRASÍLIA, 14., 2008, Brasília. Anais... Brasília: UnB, 2008.

HARNARD, Stevan. Electronic scholarly publication: quo vadis? Serials Review, v. 21, n. 1, p. 70-72, 1995. Disponível em: $<$ http://users.ecs.soton.ac.uk/harnad/Papers/Harnad/harnad95.quo.vadis.html>. Acesso em: 10 nov. 2007. 
The Access/impact problem and the green and gold roads to open access. 2004. Disponível em: <http://eprints.ecs.soton.ac.uk/9939/1/impact.html>. Acesso em: 24 set. 2007.

HARZING, Anne-Will K.; VAN DER VAL, Ron. Google Scholar as a new source for citation analysis. Ethics in Science and Environmental Politics, v. 8, p. 61-73, 2008. Disponível em: <http://www.int-res.com/articles/esep2008/8/e008p061.pdf>. Acesso em: 20 jun. 2010.

HURD, Julie M. Models of scientific communication systems. In: CRAWFORD, Suzan; HURD, Julie M.; WILIER, Ann C. From print to electronic: the transformation of scientific communication. Medford, NJ: Information Today, 1996. p. 9 - 33.

KING, Donald W.; TENOPIR, Carol. A publicação de revistas eletrônicas: economia da produção, distribuição e uso. Ciência da Informação, Brasília, v. 27, n. 2, p. 176182, maio/ago. 1998. Disponível em: <http://www.scielo.br/pdf/ci/v27n2/king.pdf>. Acesso em: 30 out. 2007.

KRZYZANOWSKI, Rosaly Favero; FERREIRA, Maria Cecília Gonzaga. Avaliação de periódicos científicos e técnicos brasileiros. Ciência da Informação, Brasília, v. 27, n. 2, p. 165-175, maio/ago. 1998. Disponível em:

<http://revista.ibict.br/index.php/ciinf/article/viewArticle/357>. Acesso em: 05 dez. 2008.

LAGOZE, Carl; VAN DE SOMPEL, Herbert. The open archives iniciative: building a low-barrier interoperability framework. 2001. Disponível em:

<http://www.openarchives.org/ documents/jcdl2001-oai.pdf>. Acesso em: 15 out. 2007.

LANCASTER, F. W. The evolution of electronic publishing. Library Trends, Urbana, v.43, n. 4, p. 518-527, 1995. Disponível em:

<http://findarticles.com/p/articles/mi m1387/is n4 v43/ai 17096178>. Acesso em:

04 nov. 2007.

LAWRENCE, S. Free online availability substantially increases a paper's impact. Nature, v. 411, n. 521, may 2001. Disponível em:

<http://www.nature.com/nature/journal/v411/n6837/full/411521a0.html>. Acesso em: 04 nov. 2007.

LEWIS, Paul (Ed.).Ethnologue: languages of the World. $16^{\text {th }}$. ed. Dallas: SIL International, 2009. Disponível em: <http://www.ethnologue.com>. Acesso em: 12 jun. 2010.

MACHADO-DA-SILVA, Clóvis L et al. Periódicos brasileiros de Administração: análise bibliométrica de impacto no triênio 2005-2007. RAC-Eletrônica, Curitiba, v. 2, n. 3, p. 351-373, set./dez. 2008. Disponível em:

<http://www.anpad.org.br/periodicos/arq pdf/a 821.pdf>. Acesso em: 10 fev. 2009. 
MÁRDERO ARELLANO, Miguel Ángel; SANTOS, Regina dos; FONSECA, Ramón da. SEER: disseminação de um sistema eletrônico para editoração de revistas científicas no Brasil. Arquivística.net, Rio de Janeiro, v. 1, n. 2, p. 75-82, jul./dez. 2005. Disponível em: <http://dici.ibict.br/archive/00000897/02/AN-2005-33[1].pdf>. Acesso em: 16 out. 2007.

MEADOWS, Arthur Jack. A comunicação científica. Brasília: Briquet de Lemos, 1999. 268p.

MEIRELLES, Rodrigo França. O Sistema Eletrônico de Editoração de Revistas (SEER) e sua adoção em periódicos brasileiros. Arquivística.net, Rio de Janeiro, v. 2, n. 2, p. 197-207, ago./dez. 2006. Disponível em: $<$ www.arquivistica.net/ojs/include/getdoc. $p h p ? i d=306 \&$ article $=88 \&$ mode $=p d f>$. Acesso em: 20 out. 2007.

MORENO, Fernanda Passini; MÁRDERO ARELLANO, Miguel Ángel. Publicação científica em arquivos de acesso aberto. Arquivística.net, Rio de Janeiro, v. 1, n. 1, p. 76-86, jan./jun. 2005. Disponível em: <http://dici.ibict.br/archive/00000908/01/AN2005-5[1].pdf>. Acesso em: 21 out. 2007.

MUELLER, Suzana P. M. A publicação da ciência: áreas científicas e seus canais preferências. DataGramaZero, v. 6, n. 1, fev. 2005. Disponível em: $<$ http://dgz.org.br/fev05/Art 02.htm>. Acesso em: 15 maio 2010.

. O periódico científico. In: CAMPELLO, Bernadete Santos; CÉNDON, Beatriz Valadares; KREMER, Jeanette Marguerite (Org.). Fontes de informação para pesquisadores e profissionais. Belo Horizonte: UFMG, 2003. p. 73-96.

MUGNAINI, Rogério; STREHL, Letícia. Recuperação e impacto da produção científica na era Google: uma análise comparativa entre o Google Acadêmico e a Web of Science. Encontros Bibli, Florianópolis, v. 13, n. esp, 2008. Disponível em: $<$ http://www.periodicos.ufsc.br/index.php/eb/article/view/1127>. Acesso em: abr. 2010.

NARIN, F. Evaluative bibliometrics: the use of publication and citation analysis in the evaluation of scientific activity. Cherry Hill, NJ: Computer Horizons, 1976. p. 169.

SCIENTIFIC ELECTRONIC LIBRARY ONLINE. Critérios SciELO Brasil: critérios, política e procedimentos para a admissão e a permanência de periódicos científicos na coleção SciELO Brasil. Outubro de 2004. Disponível em: $<$ http://www.scielo.br/criteria/scielo brasil pt.html>. Acesso em: 08 fev. 2009.

STUMPF, Ida Regina Chitto. Avaliação das revistas de comunicação pela comunidade acadêmica da área. Em Questão, Porto Alegre, v. 9, n. 1, p. 25-38, jan./jun. 2003. Disponível em:

$<$ http://www.seer.ufrgs.br/index.php/EmQuestao/article/view/57/17>. Acesso em: 10 mai. 2010. 
Avaliação pelos pares nas revistas de comunicação: visão dos editores, autores e avaliadores. Perspectivas em Ciência da Informação, v. 13, n. 1, p. 18-32, jan./abr. 2008. Disponível em: <http://www.scielo.br/pdf/pci/v13n1/v13n1a03.pdf>. Acesso em: 12 jun. 2010.

. Passado e futuro das revistas científicas. Ciência da Informação, Brasília, v. 25, n. 3, 1996. Disponível em:

<http://revista.ibict.br/index.php/ciinf/article/view/463/422>. Acesso em: 04 nov. 2007.

SUBER, Peter. Removing barriers to research: an introduction to open access for librarians. College and Research Libraries News, v. 64, n. 2, feb. 2003. Disponível em:

$<$ http://news.ala.org/ala/acrl/acrlpubs/crlnews/backissues2003/february1/removingbar riers.htm>. Acesso em: 16 set. 2007.

TAGUE-SUTCLIFFE, Jean. An introduction to informetrics. Information Processing and Management, v. 28, n. 1, p. 1-3, 1992.

TENOPIR, Carol; KING, Donald W. A importância dos periódicos para o trabalho científico. Revista de Biblioteconomia de Brasília, v. 25, n. 1, p. 15-26, jan/jun. 2001.

THOMSON SCIENTIFIC. The Thomson Scientific journal selection process.

Disponível em:

$<$ http://www.thomsonreuters.com/business units/scientific/free/essays/journalselectio n/>. Acesso em: 05 fev. 2009.

TRZESNIAK, Piotr. A estrutura editorial de um periódico científico. In: SABADINI, Aparecida; SAMPAIO, Maria Imaculada; KOLLER, Sílvia Helena (Org.). Publicar em psicologia: um enfoque para a revista científica. São Paulo: Associação Brasileira de Editores Científicos de Psicologia, 2009.

As dimensões da qualidade dos periódicos científicos e sua presença como instrumento da área da educação. Revista Brasileira de Educação, São Paulo, v. 11, n. 32, p. 346-361, maio/ago. 2006. Disponível em:

$<$ http://www.periodicos.ufrgs.br/admin/sobrelinks/arquivos/As dimensoes da qualid ade.pdf >. Acesso em: 20 nov. 2008.

VALERIO, Palmira Moriconi. Espelho da ciência: avaliação do programa setorial de publicações em ciência e tecnologia da Finep. Rio de janeiro: Finep, 1994. 132 p.

VAN DE SOMPEL, Herbert; LAGOZE, Carl. The Santa Fe convention of the open archives iniciative. D-lib Magazine, v. 6, n. 2, Feb. 2000. Disponível em:

$<$ http://www.dlib.org/dlib/ february00/vandesompel-oai/02vandesompel-oai.html>. Acesso em: 24 out. 2007.

WILLINSKY, John. Ten flavors of open access. In: . The access principle: the case of open access to research and scholarship. London: MIT, 2006. p. 211-216. 
YAMAMOTO, Oswaldo Hajime et al. Avaliação de periódicos científicos brasileiros da área de psicologia. Ciência da Informação, Brasília, v. 31, n. 2, p. 163-177, maio/ago. 2002.

YAMAMOTO, Oswaldo Hajime; COSTA, Ana Ludmila Freire. A avaliação de periódicos científicos brasileiros da área da psicologia. In: SABADINI, Aparecida; SAMPAIO, Maria Imaculada; KOLLER, Sílvia Helena (Org.). Publicar em psicologia: um enfoque para a revista científica. São Paulo: Associação Brasileira de Editores Científicos de Psicologia, 2009. 